\title{
Probability functions to build composite indicators: a methodology to measure environmental impacts of genetically modified crops
}

Article

Accepted Version

Areal, F. J. and Riesgo, L. (2015) Probability functions to build composite indicators: a methodology to measure environmental impacts of genetically modified crops.

Ecological Indicators, 52. pp. 498-516. ISSN 1470-160X doi: https://doi.org/10.1016/j.ecolind.2015.01.008 Available at https://centaur.reading.ac.uk/38938/

It is advisable to refer to the publisher's version if you intend to cite from the work. See Guidance on citing.

To link to this article DOI: http://dx.doi.org/10.1016/j.ecolind.2015.01.008

Publisher: Elsevier

All outputs in CentAUR are protected by Intellectual Property Rights law, including copyright law. Copyright and IPR is retained by the creators or other copyright holders. Terms and conditions for use of this material are defined in the End User Agreement. 


\section{CentAUR}

Central Archive at the University of Reading

Reading's research outputs online 
1 Probability functions to build composite indicators: A methodology to

2 measure environmental impacts of genetically modified crops

3

4

5

6

7

\section{Introduction}

Since the adoption of genetically modified (GM) crops in 1996 there has been an on-going debate about the impacts of GM crops. A vast scientific research on the agronomic, economic and environmental effects of GM crops has been conducted since their adoption. Most of this research is carried out at farm-level in specific countries for different crops. Recently, a number of reviews of both the agronomic and economic impacts of GM crops worldwide has been published (Areal et al., 2013a; Brookes and Barfoot, 2008, 2012, 2013; Carpenter, 2010; Park et al., 2011; Qaim, 2009). Brookes and Barfoot (2008, 2013) and Qaim (2009) provide an overview of agronomic and economic of insect resistant $(\mathrm{Bt})$ and herbicide tolerant $(\mathrm{HT})$ crops by using available impact studies. Areal et al. (2013a) and Carpenter (2010) compiled data from a number of peer-reviewed studies to carry out further statistical analysis (i.e. metaanalysis). The mentioned reviews indicate that GM crops overall tend to outperform conventional counterparts in agronomic (i.e. higher yields) and economic terms (i.e. higher gross margins per hectare), being results more evident for Bt traits. Areal et al. (2013a, 2013b) show that the agronomic and economic performance of GM crops occurs in both developing and developed countries, providing evidence that the adoption of GM crops in developing countries may contribute to increase global food security.

Potential environmental effects associated with the adoption of GM crops have been analysed at different levels: crop biodiversity, farm and landscape scales (Carpenter, 2011). Concerns on crop genetic biodiversity have been raised with the introduction of GM crops due to both the agricultural risks on cross-pollination between neighbouring GM and conventional fields through pollen transfer and seed (Bannert, 2006; Bonny, 2008; Breckling et al., 2011; Devos et al., 2005 and 2009; Graef et al., 2007; Hayes et al., 2004; Riesgo et al., 2010) and the fact that breeding programs are concentrated on a smaller number of high-value cultivars (Ammann, 2005). A reduction of crop genetic biodiversity may have significant consequences on the vulnerability of agricultural systems since crop diversity contributes to minimise the risk of harvest failures due to climate change, especially in poor farming systems (Frison et al., 2011; Padulosi et al., 2011). Declining crop genetic biodiversity may also erode the nutritional enrichment of diets based on greater supply diversity and increases 
potential risks for health (Jacobsen et al., 2013). However, despite the concerns on crop diversity several studies show that GM crops have not negatively affected genetic crop diversity in a significant manner (Bowman et al., 2003; Gepts and Papa, 2003; Sneller, 2003; Palaudelmás et al., 2009) or even that GM crops have actually increased crop diversity (Bhattacharjee, 2009; Gressel, 2008).

GM crops impacts at farm and landscape levels include any effects on organisms that live within or outside the farm (i.e. non-target soil organisms, weeds, non-target above-ground invertebrates and birds) and effects on pesticide ${ }^{1}$ use. Potential environmental benefits of the adoption of HT crops have been raised by some authors, such as the substitution of selective herbicides (usually harmful for the environment) for less toxic broad-spectrum herbicides (e.g. glyphosate), savings associated with low herbicide use and the adoption of conservation tillage practices (Devos et al., 2008; Deward et al., 2003; Ervin et al., 2000; Nelson and Bullock, 2003; Smyth et al., 2011; Sydorovych and Qaim, 2009; Wolfenbarger and Phifer, 2000). However, the decrease in the total quantity of herbicides applied per unit surface area only occurs at early stages of HT crops adoption (Bonny, 2008; Owen and Zelaya, 2005; Shaner, 2000), but a rise in the quantity of herbicides is expected in late stages of adoption due to the presence of resistant weeds. It is worth mentioning that some of these potential impacts such as the substitution of selective herbicides and the adoption of conservation tillage practices are not directly caused by the GM plant but by the farm management practices associated with the cultivation of HT crops. In the case of Bt crops some authors pointed out a positive impact caused through the reduction of pesticide use not only on GM fields but also on neighbouring conventional fields ("halo effect") (Carriére et al., 2003; Wan et al., 2012; Mannion and Morse, 2012). One of the earliest studies on farm biodiversity was the UK Farm Scale Evaluations (FSE) of genetically modified herbicide tolerant (GMHT) crops, which included analysis on sugar beet, winter oilseed rape (WOSR), spring oilseed rape (SOSR) and maize (Squire et al., 2003; Heard et al., 2003a, 2003b; Haughton et al., 2003). The main results from the UK FSE regarding invertebrates indicate that whereas certain species such as butterflies may be negatively affected by the adoption of some GMHT crops (HT sugar beet and HT SOSR) other species such as springtails and some of their predators were more abundant. Also butterflies were positively affected by the adoption of HT maize (Haughton et al., 2003). With respect to plant densities less densities were found in HT beet and HT oilseed rape whereas more plant density was found in HT maize than in their

\footnotetext{
${ }^{1}$ Pesticide use includes both herbicides and insecticides use.
} 
conventional counterparts (Heard et al., 2003a). As a result of research studying the environmental effects associated with the adoption of GM crops a number of reviews have been published compiling data and given an overview of environmental impacts of GM crops (Amman, 2006; Carpenter, 2011; Sanvido et al., 2007; Wesseler et al., 2011).

Environmental effects of GM crops when compared to their conventional counterparts are diverse in the literature, being measured those impacts using an array of indicators such as number of individuals, number of individuals per 100 plants, mg per square meter, number of sprays, $\mathrm{kg}$ of active ingredient, $\mathrm{kg}$ of pesticide per ha and litre per ha. Considering the type of impact, these eight indicators can be grouped into: a) indicators related to measuring impacts on non-target key species richness ((see Table A1 in the Appendix) and b) indicators related to the pesticide ${ }^{2}$ use (see Table A2 in the Appendix).

In addition to these indicators, some studies used some indicators to assess the risk of pesticides on humans and animals in order to evaluate the environmental impact of GM crops. The biocide index (Jansen et al., 1995) and the field use rating of the Environmental Impact Quotient (EIQ) developed by Kovach et al. (1992) are usually used to measure and compare the relative environmental impacts of GM crops (Morse et al, 2006; Brookes and Barfoot, 2005, 2008, 2013; Smyth, 2011). The EIQ is a tool to assess specific pesticide risk to farmers, consumers and the environment. More specifically environmental and health impacts of pesticides are calculated by incorporating potential toxicity values for specific pesticides considering the degradation and transportation rates (Knox et al., 2012). The main difficulty to use these indicators is data requirements on the type and rate use of pesticides.

In this paper we are interested on taking advantage of the information published to date on some environmental effects of GM crops when compared to conventional crops, in order to obtain some conclusions on the potential environmental impacts of GM crops adoption ${ }^{3}$. We propose first to build a composite indicator that allows to aggregate data published by several authors on environmental effects of GM and conventional crops ${ }^{4}$. Different normalisation

\footnotetext{
${ }^{2}$ Pesticide use include both herbicide and insecticide use.

${ }^{3}$ Please note that this paper only compares the environmental effects of GM and conventional crops, but organic crops are not included in the analysis. An analysis including organic crops cannot be performed since there is no enough published data available to perform the statistical analysis (data on non-target species richness and pesticide use for both organic and GM crops in similar edafoclimatic conditions). However, a comparative analysis of the environmental performance of both organic and GM crops would be of interest. Some meta-analysis conduct a comparative analysis of the environmental effects caused by organic and conventional crops (Mondelaers et al., 2009; Azadi and Ho, 2010; Tuomiso et al., 2012). Results show that organic farming has generally lower environmental impacts per unit of area than conventional farming.

${ }^{4}$ This paper is focused on the environmental impacts associated with the cultivation of GM crops at farm level.
} 
procedures are analysed in order to aggregate the different indicators forming the composite indicator. Robustness of the constructed composite indicators is assessed by assigning different weights to the indicators and changing the aggregation method. Secondly, a metaanalysis of environmental impacts of GM and non-GM crops is conducted to examine whether GM crops performs environmentally better than their conventional counterparts.

\section{Methods}

Composite indicators aim to aggregate indicators that measure impacts on different fields (e.g. economic, social and/or environmental dimensions) in order to obtain a unique value. In this paper we are not interested in measuring dimensions like economic or social impacts of GM crops but environmental. Taking advantage of how a composite indicator is built we develop a methodology to aggregate data on some key environmental impacts of GM crops that have been published in a number of scientific articles.

The main issues in building a composite indicator are related to normalization, weighting and aggregation of indicators as well as the robustness of the composite indicator. Nardo et al. (2005) and OECD (2008) suggest a number of alternative techniques for this purpose, explaining their pros and cons. The most popular methods are based on the weighted sum of indicators (Andreoli and Tellarini, 2000; Rigby et al., 2001; Gómez-Limón and Riesgo, 2009), principal component analysis (Sands and Podmore, 2000), analytic hierarchy process (Pirazzoli and Castellini, 2000), geometric average (Qiu et al., 2007, Gómez-Limón and Sánchez-Fernández, 2010) or multiattribute utility functions (van Calker et al., 2006). The weight given to each indicator shows their contribution to the final composite indicator. We use here two aggregation rules of individual indicators: additive and multiplicative aggregation. The additive approach ${ }^{5}$ is based on a linear weighted aggregation rule implying total compensation among indicators (i.e. allow to compensate one indicator with bad score with another with good score), whereas the multiplicative approach is based on the product of weighted indicators ${ }^{6}$ allowing only partial compensation (i.e. still bad scores can be compensated with good scores but not linearly, thus only partial compensation is accounted for) (OECD, 2008).

\footnotetext{
${ }^{5} C I_{a}=\sum_{i} w_{i} \cdot I_{i}$, where $C I$ is the composite indicator following an additive approach, $I_{i}$ is the indicator and $w_{i}$ is the weight.

${ }^{6} C I_{m}=\prod_{i} I_{i}{ }^{w_{i}}$, where $C I$ is the composite indicator following a multiplicative approach, $I_{i}$ is the indicator and $w_{i}$ is the weight.
} 
120 Normalization is a prerequisite for any aggregation of indicators because they are usually measured in different units. Taking into account the indicators found in the literature review on the environmental impact measures/indicators of GM crops and conventional crops we use two different normalisation methods: a) the min-max and b) the distance to a reference point.

The min-max method normalises the indicator by subtracting the minimum value and dividing by the range of indicator values as shown in the following equation:

$$
I_{i}=\frac{x_{i}-\min (x)}{\max (x)-\min (x)}
$$

where $x$ is an indicator vector that contains values of environmental impact (e.g. number of individuals (arthropods)).

The distance method normalises the indicator by measuring the relative position of an indicator to a reference point, which in this case is the maximum value of the sample as shown in equation 2.

$$
I_{i}=\frac{x_{i}}{\max (x)}
$$

Both methods allows re-scaling indicators within a dimensionless range $[0,1]$ for the minmax method and $(0,1]$ for the distance normalisation method. Indicators can be classified into two groups: "more is better" indicators (e.g. indicators related with biodiversity richness: arthropods number, worms weight, birds) and "less is better" indicators" (e.g. indicators related with active ingredient use). In the case of a "less is better" indicator it will be transformed in "more is better indicator" by multiplying by -1. After normalization all indicators will have a value that range between 0 or close to 0 (the worst value, e.g. the minimum number of arthropods or the maximum quantity of active ingredient use) and 1 (the best value, e.g. the maximum number of arthropods or the minimum quantity of active ingredient use).

\footnotetext{
${ }^{7}$ All environmental indicators related with the pesticide use are of type "less is better". The use of these pesticides allows us to compare the use of the same pesticide among GM and conventional crops. We acknowledge that the use of some pesticides is more harmful (or toxic) for the environment than others (e.g. one $\mathrm{kg}$ of arsenic is more toxic than one $\mathrm{kg}$ of salt). This issue is of great importance in the case of HT crops, since this type of crop sometimes implies an increase in the amount of broad spectrum herbicides (pesticides) when compared with conventional counterparts, but with lower toxicity than specific herbicides against weeds used in conventional crops. This analysis does not take into account the toxicity of the pesticide in the environment, but assumes that it is better to use less pesticide than more.
} 
147 A number of studies based on sample surveys compared the environmental impact of GM 148 crops and conventional crops at farm level in different countries (see Tables A-1 and A-2). 149 Data on environmental impacts were collated from peer-review studies and grouped into 8 150 different indicators (4 related to non-target key species richness and 4 related to pesticide use) 151 to conduct the analysis (see Figure 1). As it is mentioned above we take advantage of the 152 information published to date on some environmental effects of GM crops when compared to 153 conventional crops. In this literature different indicators were used to analyse environmental 154 impacts such as the number of individuals (arthropods); number of individuals (birds); 155 number of individuals per 100 plants (arthropods); earthworm weight (in mg per square 156 meter); number of sprays; $\mathrm{kg}$ of active ingredient per ha; $\mathrm{kg}$ of pesticide per ha; and litre of 157 pesticide per ha. Data for non-target species richness were collated from studies based on 158 field trials, where a number of plots were used to investigate the abundance of certain non159 target species in fields grown with GM and conventional crops. Data for pesticide use were 160 gathered from studies based on surveys at farm level and consequently no further information 161 from farmers associations at market level or extension services are included in the analysis. 162 Consequently, the environmental impacts are limited to farm level. The 8 indicators on 163 environmental impacts were used to calculate two composite indicators: 1) one for the environmental impact related to non-target key species richness and 2) another for the environmental impact related to pesticide use. These two composite indicators are then used to calculate a third composite indicator that measures the aggregated environmental impact. 


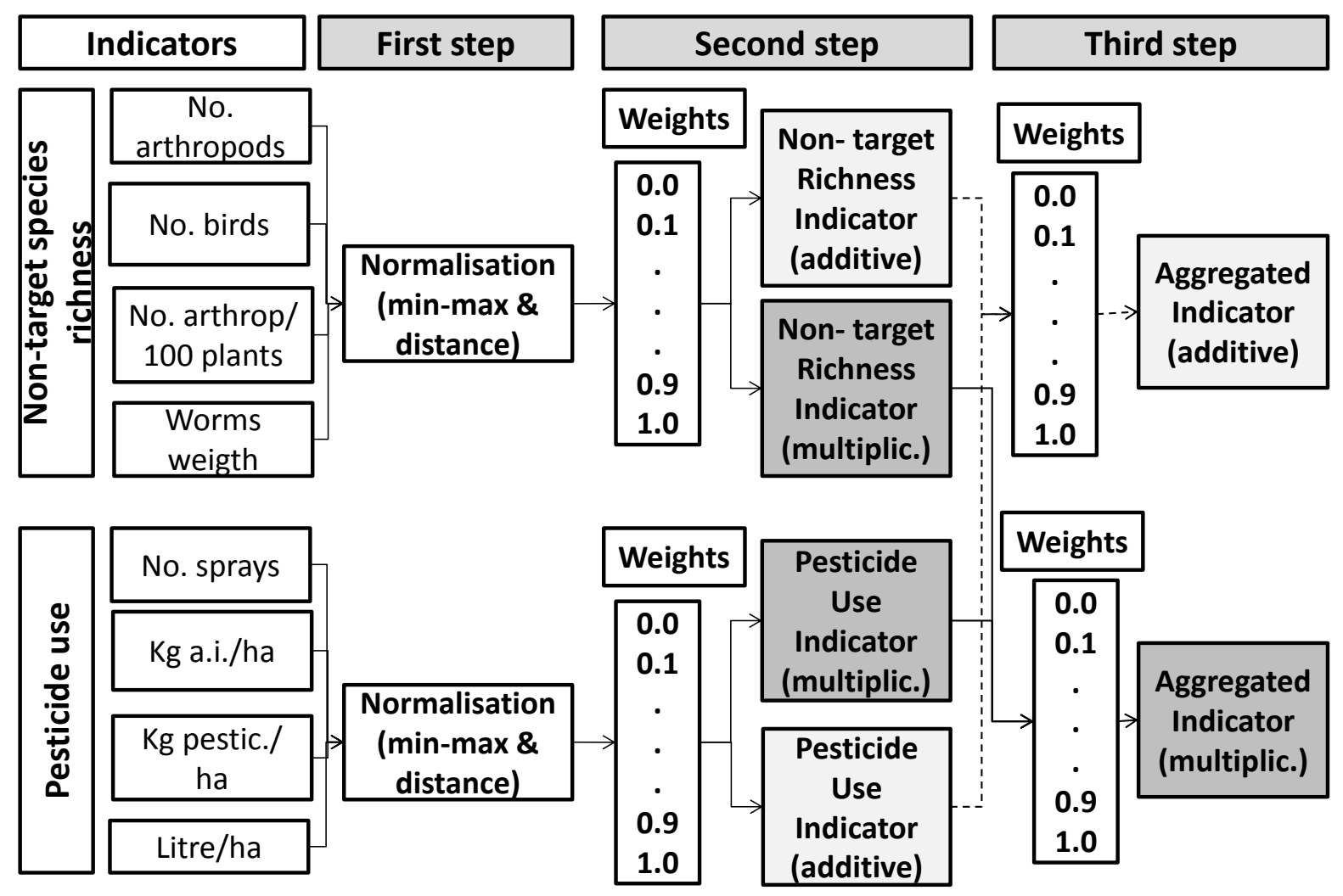

171 As far as we are concerned, all the studies using composite indicators are based on single 172 values of the individual indicators. The analyses conducted consist of normalising and 173 aggregating those single values to build a composite indicator. In this paper, we calculate two 174 environmental composite indicators, one for GM and another for conventional crops by using 175 data compiled from a number of peer-review studies ${ }^{8}$. Data collected from these studies show 176 one observation (i.e. an average value) on either non-target key species richness or pesticide 177 use per type of crop (i.e. one data for GM and another for conventional crops). Since data 178 used are an average value we calculate each environmental composite indicator on the basis 179 of the distribution of the mean of each indicator per crop information in order to take 180 advantage of the information published on the sample size. This allows us to assign more 181 (less) weight to the data provided by studies that contained more (less) information (i.e. 182 studies with large (small) samples).

\footnotetext{
${ }^{8}$ Large datasets on pesticide use at country level, such as national pesticide use surveys or the analyses published by Brookes and Barfoot $(2012,2013)$ on pesticide use and other environmental impacts, are not included in this analysis due to the different scale of analysis (this paper only collates data from papers analysing environmental impacts at farm level -real farms or field trials at farm level-).
} 
The environmental indicators were selected on the basis of the literature on environmental impacts of GM and conventional crops, and no assumptions are made about the relative importance of each indicator within the environmental composite indicator. Hence, we calculate the mean of the posterior probability density function (pdf) of the composite indicator for the environmental impact of GM and conventional crops for all possible combinations of weighting (at one decimal level) ${ }^{9}$.

Therefore we can a) compare the environmental impact related to non-target key species richness of GM vs. conventional crops (i.e. build a composite indicator for non-targeted key species richness for each crop and calculate afterwards the probability that GM crops perform better than conventional crops); b) compare the environmental impact related to pesticide use of GM vs. conventional crops (i.e. build a composite indicator for pesticide use for each crop and after that calculate the probability that GM crops perform better than conventional crop); and c) compare total environmental impact of GM vs. conventional crops using the two mentioned composite indicators (i.e. build an aggregated composite indicator considering both non-targeted key species richness and pesticide use composite indicators, and calculate afterwards the probability that GM crops perform environmentally better than conventional crops).

Bayesian and non-parametric methods were used to make inferences about the environmental performance of GM crops in comparison with conventional crops per indicator ${ }^{10}$. We tested for normality of the errors for each indicator per normalisation method and crop. We selected the method based on the results obtained from the normality tests ${ }^{11}$. Three possible approaches were possible: 1) if the normality assumption is not rejected a Bayesian linear analysis (BLA) assuming normally distributed errors is conducted; 2) if the normality assumption is rejected but the distribution is not skewed we assume a less restrictive Student's $t$ distribution for the errors than the Bayesian linear analysis; and 3) if the normality assumption is rejected and the distribution is skewed a non-parametric bootstrapping approach is conducted.

\footnotetext{
${ }^{9}$ A detailed explanation of the process can be found below under Section 2.4.

${ }^{10}$ For a detailed and comparative analysis of parametric and non-parametric statistical methods see Sheskin (2004).

${ }^{11}$ We tested for normality using the Jarque-Bera test. The sample skewness statistics is calculated by using: $=m_{3} / m_{2}^{3 / 2}$, where $m_{3}$ is the sample third central moment and $m_{2}$ is the sample variance. If the value of the estimate of skewness exceeds two times the standard error of skewness (calculated as $S E S=\sqrt{6 / N}$ ) then the sample distribution is regarded as skewed (Tabachnik and Fidell, 1996) and non-parametric bootstrap is carried out.
} 


\subsection{The Bayesian linear analysis}

212 For each indicator there are $N$ independent observations $y^{\prime}=\left(y_{1}, y_{2}, \ldots, y_{N}\right)$ which are

213 assumed to be drawn from a Normal distribution with mean $\mu$ and variance $\sigma^{2} / n_{i}$ where $n_{i}$ is

the number of observations of study $i$. Therefore, each indicator equals its mean plus some zero-centred normally distributed error term $\varepsilon_{i} \sim N\left(0_{N}, h^{-1} I_{N} / n_{i}\right)$, where $h=1 / \sigma^{2}$ is the error precision and $I_{N}$ is the $N \times N$ identity matrix. The linear regression model to be estimated is $y_{i}^{*}=\sqrt{n_{i}} \mu+v_{i}$, with $y_{i}^{*}=\sqrt{n_{i}} y_{i}, \operatorname{Var}\left(v_{i}\right)=\sigma^{2}$ and $v_{i}=\varepsilon_{i} \sqrt{n_{i}}$.

Bayesian methods were used to infer the environmental impact of both GM and conventional crops in the case that errors distribution of the indicator $I$ for the type crop was normally distributed. The Bayesian approach treats parameters as random variables and yields distributional information. The Bayes theorem can be represented in the following expression:

$$
p(\theta \mid y) \propto p(\theta) p(y \mid \theta)
$$

where $p(\theta \mid y)$ is the posterior probability density function (pdf) for the parameter vector $\theta$, given the sample information $y ; p(\theta)$ is the prior information for the parameter vector $\theta$; and $p(y \mid \theta)$ is the likelihood function, which is a pdf of the observations given the parameters. In the Bayesian approach inferences about the parameters are made using the posterior pdf. In this analysis our parameters of interest are the means of the indicators for environmental impact.

The likelihood function is defined by the assumption of normally distributed errors:

$$
p\left(y^{*} \mid \mu, h\right)=\frac{h^{N / 2}}{(2 \pi)^{N / 2}} \exp \left(-\frac{h}{2}\left(\sum_{i=1}^{N} y_{i}^{*}-\sqrt{n_{i}} \mu\right)^{2}\right)
$$

The likelihood function shown in equation [4] is complemented with a prior distribution on parameters $\mu$ and $h$. We use natural conjugate priors that when combined with the likelihood distribution yields a posterior that falls under the same class of distributions. An independent 
conditional posterior distributions for $\mu$ and $h$ followed normal and gamma distributions. The prior distribution for the mean is:

$$
p(\mu) \propto \exp \left(\frac{h_{0}}{2}\left(\mu-\mu_{0}\right)^{2}\right)
$$

where $\mu_{0}$ and $h_{0}$ are the mean prior and the inverse variance prior distributions with values 0.5 and 0.1 , respectively, making the prior non-informative (i.e. the mean prior of each indicator was given a variance of 10 units which means that no prior information is given for this parameter). The prior distribution for the error precision is given by the following expression:

$$
p(h) \propto h^{a-1} \exp \left(-\frac{a}{c}\right), h>0
$$

where $a$ and $c$ are hyperparameters with values 0.01 and 2,500 respectively ${ }^{12}$. These values put little weight to the prior information making the prior relatively non-informative. The Bayesian computation of the conditional posteriors was carried out using a Gibbs sampler (Geman and Geman, 1984). A total number of 1,200 random draws were generated from the conditional distributions with 200 draws discarded and 1,000 retained. These 1,000 draws could be considered a sample from the joint posterior density function of the parameters.

\subsection{The Student's $t$ distributed errors}

This approach is the same as for the normally distributed errors case, with the exception that now $v_{i} \sim N\left(0_{N}, h^{-1} \lambda_{i}^{-1}\right)$ for $i=1, \ldots, N$ is assumed, where $\lambda=\left(\lambda_{1}, \lambda_{2}, \ldots, \lambda_{N}\right)^{\prime}$ is a vector of error precisions. Following Koop (2003) we incorporate the new parameter $\lambda$ into the Bayesian analysis. The prior for $\lambda$ is $(\lambda)=\prod_{i=1}^{N} f_{G}\left(\lambda_{i} \mid 1, \tau_{\lambda}\right)$, which is the exponential distribution with hyperparameter $\tau_{\lambda}$. We set $\tau_{\lambda}=25$ which allocated substantial prior weight to both fat-tailed error distributions as well as error distributions which were roughly Normal (Koop, 2003). The conditional posterior distribution of the new parameters $\lambda_{i}$ had the form of a Gamma density, whereas the conditional posterior distribution for $\tau_{\lambda}$ was not a standard one

\footnotetext{
${ }^{12}$ These values are based on the expectation that the errors in the environmental indicators are of the order of magnitude of 0.1 to 0.2 units. We set a value for the standard deviation of $h$ of 0.2 which gives a mean for the prior distribution of $h$ of 25 . We assign little weight to the prior information about $h$ by setting the variance of the prior distribution of $h$ in 62,500.
} 
and a Random Walk Chain Metropolis-Hastings algorithm (Hastings, 1970; Chib and Greenberg, 1995) was used to obtain the distribution.

$$
\begin{aligned}
& p\left(\lambda_{i} \mid y^{*}, \mu, h, \tau_{\lambda}\right)=f_{G}\left(\lambda_{i} \mid \frac{\tau_{\lambda}+1}{v_{i}^{2}+\tau_{\lambda}}, \tau_{\lambda}+1\right) \\
& p\left(\tau_{\lambda} \mid y^{*}, \mu, h, \lambda\right) \propto\left(\frac{\tau_{\lambda}}{2}\right)^{\frac{N \tau_{\lambda}}{2}} \Gamma\left(\frac{\tau_{\lambda}}{2}\right)^{-N} \exp \left(-\eta \tau_{\lambda}\right)
\end{aligned}
$$

where $\eta=\frac{1}{\underline{\tau}_{\lambda}}+\frac{1}{2} \sum_{i=1}^{N}\left[\ln \left(\lambda_{i}\right)^{-1}+\lambda_{i}\right]$. The conditional posterior distribution for $\mu, h$ and $\lambda$ were obtained using a Gibbs sampler in the same way as in the linear analysis.

\subsection{The non-parametric Bootstrapping residuals method}

The non-parametric Bootstrapping residuals method (Efron and Tibshirani, 1993) is a resampling method for statistical inference where no distributional parameters are given. This is used to estimate the mean of the distribution of each indicator $\mu$ for both types of crops (i.e. GM and conventional). The method has three steps: (1) calculating approximate errors using the least square estimate of $\mu(\hat{\mu})$; (2) drawing the approximate errors 1,000 times with replacement to obtain $v_{i}^{* *}$; and (3) using these to generate $y_{i}^{* *}=\hat{\mu}+v_{i}^{* *}$.

\subsection{Building composite indicators}

Regardless of the approach used we obtained a density function with 1,000 elements for each indicator vector which allowed us to construct composite environmental indicators for each type of crop (i.e. GM and conventional). Therefore we build a $1,000 \times 4$ matrix $R I_{j}$ with the 4 indicators associated with non-target key species richness per crop type $j$ (GM crop, conventional crop) and a 1,000 $\times 4$ matrix $P I_{j}$ with the 4 indicators associated with pesticide use per crop type $j$. In order to build a composite indicator we need to weight and aggregate the individual indicators matrices $R I_{j}$ and $P I_{j}$. We generated a weighting matrix $W_{1}$ with the following characteristics: each element of $W_{1}$ can take any of the following values $\{0,0.1,0.2, \ldots, 1\}$, and the rows of the weighting matrix are combinations of elements (weights) where the sum of the elements of each row of the weighting matrix equals 1 . The total number of combinations under these characteristics of the weighting matrix $W_{1}$ is 286 . Therefore $W_{1}$ is a $286 \times 4$ (i.e. one column per indicator) weighting matrix. 
We construct two $1,000 \times 286$ composite indicator matrices, one for non-target key species richness $\left(C R I_{j}\right)$ and another for pesticide use $\left(C P I_{j}\right)$ per crop $j$, each containing 286 columns (i.e. composite indicators) as below:

$$
\begin{gathered}
C R I_{j}=R I_{j} \times W_{1}^{\prime} \\
C P I_{j}=P I_{j} \times W_{1}^{\prime}
\end{gathered}
$$

The matrices $C R I_{j}$ and $C P I_{j}$ effectively have: (a) 286 composite indicators (mean values of the distribution function) for environmental impact related to non-target key species richness and (b) 286 composite indicators for environmental impact related to pesticide use.

Finally, in order to obtain an overall composite indicator matrix $O C I_{j}$ per crop type $j$ we conduct the following steps: (1) stacking the columns of $C R I_{j}$ and $C P I_{j}$ obtaining two $286,000 \times 1$ vectors: $c r i i_{j}$ and $c p i_{j}$ per crop type $j$; (2) forming a 286,000 $\times 2$ matrix using $c r i_{j}$ and $c p i_{j}$; (3) generating a $11 \times 2$ (i.e. one column per indicator) weighting matrix ${ }^{13} W_{2}$ which elements can take $\{0,0.1,0.2, \ldots, 1\}$ as values and the sum of the elements of each row equals 1 ; and (4) constructing $O C I_{j}$ as follows:

$$
O C I_{j}=\left[c r i_{j} c p i_{j}\right] \times W_{2}^{\prime}
$$

The resulting $O C I_{j}$ is a $286,000 \times 11$ matrix per crop type $j$. This allows us to compare the environmental impact of both crops per composite indicator and calculate the probability that a GM crop performs environmentally better than its conventional counterpart.

\section{Results}

Results are organised as follows: first, the impacts of GM and conventional crops are presented by considering all environmental indicators individually. Secondly, the impacts of both crop types on the non-target key species richness and the pesticide use is presented through composite indicators and finally, the impact of both crops on the aggregated environmental indicator is shown.

\footnotetext{
${ }^{13}$ Taking into account that we consider all possible combinations of weighting at one decimal level (from 0.0 to 1.0 ) and that the sum of all that combinations must be 1.0, there are 11 possible weighting combinations when using two indicators.
} 
331 Table 1 shows the type of approach used based on the assumption about the errors to obtain a density function for each indicator.

Table 1. Type of approach

\begin{tabular}{|c|c|c|c|c|c|}
\hline \multirow{2}{*}{$\begin{array}{l}\text { Indicator } \\
\left.\text { (Positive }^{a}\right)\end{array}$} & \multicolumn{2}{|c|}{ Non-target key species richness } & \multirow{2}{*}{$\begin{array}{l}\text { Indicator } \\
\left(\text { Negative }^{b}\right)\end{array}$} & \multicolumn{2}{|c|}{ Pesticide use } \\
\hline & GM & Conventional & & GM & Conventional \\
\hline $\begin{array}{l}\text { I1. No. of } \\
\text { individuals } \\
\text { (arthropods) }\end{array}$ & Bootstrapping & Bootstrapping & $\begin{array}{l}\text { I5. No. of } \\
\text { sprays }\end{array}$ & Bootstrapping & Bootstrapping \\
\hline $\begin{array}{l}\text { I2. No. of } \\
\text { individuals } \\
\text { (birds) }\end{array}$ & Linear & Bootstrapping & $\begin{array}{l}\text { I6. } \mathrm{Kg} \text { of } \\
\text { active } \\
\text { ingredient }\end{array}$ & Linear & Linear \\
\hline $\begin{array}{l}\text { I3. No. of } \\
\text { individuals } \\
\text { (arthropods)/100 } \\
\text { plants }{ }^{14}\end{array}$ & Bootstrapping & Bootstrapping & $\begin{array}{l}\text { I7. } \mathrm{Kg} \text { of } \\
\text { pesticides }\end{array}$ & Bootstrapping & Bootstrapping \\
\hline $\begin{array}{l}\text { I4. Earthworm } \\
\text { weight }\end{array}$ & Bootstrapping & Bootstrapping & $\begin{array}{l}\text { I8. Litre of } \\
\text { pesticides } \\
\text { per ha }\end{array}$ & Bootstrapping & Bootstrapping \\
\hline
\end{tabular}

Figures A-1a (min-max normalising method) and A-1b (normalising method using distance) in the Appendix show the density functions for the 8 environmental impact indicators for GM and conventional crops. In addition, the probability that GM crops perform environmentally better than conventional crops per indicator is calculated in Tables 2 and A- $3^{15}$. Results show that GM crops outperform conventional crops in three indicators related with pesticide use, such as number of sprays, $\mathrm{kg}$ of active ingredient and $\mathrm{kg}$ of pesticide per ha (i.e. probability higher than 98\%), regardless of the normalisation approach. For the rest of indicators GM crops tend to perform better than conventional crops (probability higher than 50\%) except for the number of arthropods (i.e. the probability that GM crops have a lower impact than conventional crops on non-target species is negligible) and the indicator litre per ha (i.e. GM crops are more harmful for the environment than conventional).

\footnotetext{
${ }^{14}$ Two indicators on the number of arthropods were selected in this study (II and I3). While II measures the absolute abundance of arthropods in a plot 13 measures a relative density of arthropods per number of plants. Since both indicators show different dimensions (and units of measures), they cannot be added together and consequently they were considered as different components of the composite indicator on non-target key species richness.

${ }^{15}$ Table A-1 can be found in the Appendix.
} 
Table 2 shows the mean values of each normalised indicator for both GM and conventional crops. Values close to 1 for a specific indicator imply a high environmental performance of the crop whereas values close to 0 mean low performance of the crop in the indicator. For an indicator on non-target key species richness, e.g. number of birds, GM crops shows a value of 0.478 which is higher than the value for conventional crops $(0.446)$. This means that GM crops are slightly better than conventional crops on bird richness, and consequently more beneficial for the environment. For an indicator on pesticide use, e.g. no. of sprays, GM crops show a higher value (0.925) than conventional crops (0.867), implying that GM crops requires on average less pesticide sprays than conventional crops ${ }^{16}$, which is environmental preferable.

Table 2. Indicator results for GM and conventional crops (using the min max method)

\begin{tabular}{lccccc}
\hline \multirow{2}{*}{ Indicators } & \multicolumn{2}{c}{ GM } & \multicolumn{2}{c}{ Conventional } & \multirow{2}{*}{ Pr (GM>Conv) } \\
\hline I1. No. of individuals (arthropods) & 0.024 & 0.008 & 0.024 & 0.008 & 0.503 \\
I2. No. of individuals (birds) & 0.478 & 0.066 & 0.446 & 0.069 & 0.648 \\
I3. No. of individuals (arthropods) & 0.191 & 0.051 & 0.161 & 0.047 & 0.682 \\
per 100 plants & & & & & \\
I4. Earthworm weight $\left(\mathrm{mg} / \mathrm{m}^{2}\right)$ & 0.211 & 0.054 & 0.190 & 0.042 & 0.611 \\
I5. No. of sprays & 0.925 & 0.013 & 0.867 & 0.030 & 0.984 \\
I6. Kg active ingredient per ha & 0.752 & 0.085 & 0.330 & 0.115 & 0.998 \\
I7. Kg pesticide per ha & 0.958 & 0.019 & 0.777 & 0.067 & 0.996 \\
I8. Litre per ha & 0.421 & 0.230 & 0.714 & 0.102 & 0.130 \\
\hline
\end{tabular}

\subsection{Environmental Impact Indicators on non-target key species richness and pesticide use}

The next step consists of calculating a composite indicator to measure the environmental impact of both crops on non-target key species richness and pesticide use. Hence, for each indicator there are 286 composite indicators for GM crops (i.e. results obtained for all potential combinations of weights for individual environmental indicators) and 286 composite indicators for conventional crops, which allowed us to compare the difference in environmental impact of both crops as well as calculating the probability that one crop type performs environmentally better than the other (here we calculate the probability that GM crops perform environmentally better than conventional crops). Figure A-2 shows the densities for the composite indicators on non-target key species richness and pesticide use for

\footnotetext{
16 The indicators on pesticide use are of type "less is better", but later is transformed in "more is better" indicator. So, 0 is the worst value (maximum number of pesticides) and 1 is the best value (minimum number of pesticides).
} 
both GM and conventional crops. For each normalising approach, results for additive and multiplicative aggregation methods are also shown.

Table 3 shows that GM crops tend to perform environmentally better than conventional crops in both composite indicators, regardless aggregation method used and for the min-max normalisation method. Results for the distance normalisation method can be found in the Appendix (Table A-4). It can be seen that when the individual indicators are aggregated in composite indicators, results tend to be more favourable for GM crops, regardless of the weights given to the individual indicators included in the composite indicator.

Table 3. Non-target key species richness and pesticides use composite indicators for GM and conventional crops (using min-max normalisation and the additive/multiplicative aggregation methods)

\begin{tabular}{|c|c|c|c|c|c|}
\hline \multirow{2}{*}{ Composite indicators } & \multicolumn{2}{|c|}{ GM } & \multicolumn{2}{|c|}{ Conventional } & \multirow{2}{*}{$\operatorname{Pr}(\mathbf{G M}>$ Conv $)$} \\
\hline & Mean & Std. Dev & Mean & Std. Dev & \\
\hline \multicolumn{6}{|l|}{ Additive approach } \\
\hline $\begin{array}{l}\text { Non-target key species } \\
\text { richness CI }\end{array}$ & 0.23 & 0.09 & 0.21 & 0.08 & 0.68 \\
\hline Pesticide use CI & 0.77 & 0.13 & 0.67 & 0.12 & 0.77 \\
\hline \multicolumn{6}{|l|}{ Multiplicative approach } \\
\hline $\begin{array}{l}\text { Non-target key species } \\
\text { richness CI }\end{array}$ & 0.17 & 0.09 & 0.15 & 0.08 & 0.63 \\
\hline Pesticide use CI & 0.73 & 0.12 & 0.64 & 0.12 & 0.73 \\
\hline
\end{tabular}

390

The additive aggregation method shows slightly higher results for GM crops than the multiplicative approach in both composite indicators. Since the additive approach allows total compensation amongst individual indicators within each composite indicator, this means that GM crops have on average better results for individual indicators included in each composite indicator than conventional crops.

\subsection{Aggregated Environmental Impact Indicators}

398 Finally, by aggregating the non-target key species richness and pesticide use composite indicators we obtain 11 environmental impact composite indicators per crop (i.e. GM and conventional) depending on the weights given to each composite indicator.

401 Figure A-3 in the Appendix shows the densities for the environmental composite indicators per crop for both the min-max normalisation and the additive aggregation methods (results 
403 for the distance normalisation method and the multiplicative aggregation approach are quite 404 similar to results showed in Figure A-3). 


\begin{tabular}{|c|c|c|c|c|c|c|c|c|c|c|c|}
\hline \multirow{2}{*}{ Min-max } & \multicolumn{2}{|l|}{ GM } & \multicolumn{2}{|c|}{ Conventional } & \multirow{2}{*}{$\operatorname{Pr}(G M>C o n v)$} & \multirow{2}{*}{ Distance } & \multicolumn{2}{|l|}{ GM } & \multicolumn{2}{|c|}{ Conventional } & \multirow{2}{*}{$\operatorname{Pr}(\mathrm{GM}>$ Conv $)$} \\
\hline & Mean & Std. Dev & Mean & Std. Dev & & & Mean & Std. Dev & Mean & Std. Dev & \\
\hline Additive & & & & & & Additive & & & & & \\
\hline $\mathrm{C} 1^{17}$ & 0.77 & 0.13 & 0.67 & 0.12 & 0.77 & $\mathrm{C} 1$ & 0.70 & 0.15 & 0.61 & 0.13 & 0.80 \\
\hline $\mathrm{C} 2$ & 0.72 & 0.12 & 0.63 & 0.11 & 0.77 & $\mathrm{C} 2$ & 0.66 & 0.13 & 0.60 & 0.12 & 0.80 \\
\hline $\mathrm{C} 3$ & 0.66 & 0.11 & 0.58 & 0.10 & 0.78 & C3 & 0.61 & 0.13 & 0.53 & 0.10 & 0.80 \\
\hline C4 & 0.61 & 0.10 & 0.53 & 0.09 & 0.78 & $\mathrm{C} 4$ & 0.56 & 0.11 & 0.59 & 0.09 & 0.81 \\
\hline C5 & 0.55 & 0.09 & 0.49 & 0.08 & 0.79 & $\mathrm{C} 5$ & 0.51 & 0.10 & 0.45 & 0.09 & 0.81 \\
\hline C6 & 0.50 & 0.08 & 0.44 & 0.08 & 0.79 & C6 & 0.47 & 0.09 & 0.41 & 0.08 & 0.81 \\
\hline $\mathrm{C7}$ & 0.44 & 0.08 & 0.39 & 0.07 & 0.79 & $\mathrm{C7}$ & 0.42 & 0.08 & 0.37 & 0.08 & 0.81 \\
\hline $\mathrm{C} 8$ & 0.39 & 0.08 & 0.35 & 0.07 & 0.79 & $\mathrm{C} 8$ & 0.37 & 0.08 & 0.33 & 0.07 & 0.80 \\
\hline C9 & 0.33 & 0.08 & 0.30 & 0.07 & 0.78 & C9 & 0.32 & 0.08 & 0.29 & 0.08 & 0.78 \\
\hline C10 & 0.28 & 0.08 & 0.25 & 0.08 & 0.75 & C10 & 0.28 & 0.09 & 0.25 & 0.08 & 0.73 \\
\hline C11 & 0.23 & 0.09 & 0.21 & 0.09 & 0.68 & C11 & 0.23 & 0.10 & 0.21 & 0.09 & 0.66 \\
\hline Multiplicative & & & & & & Multiplicative & & & & & \\
\hline C1 & 0.73 & 0.17 & 0.64 & 0.14 & 0.73 & $\mathrm{C} 1$ & 0.65 & 0.18 & 0.57 & 0.14 & 0.72 \\
\hline $\mathrm{C} 2$ & 0.62 & 0.14 & 0.54 & 0.12 & 0.74 & $\mathrm{C} 2$ & 0.56 & 0.14 & 0.49 & 0.12 & 0.73 \\
\hline C3 & 0.53 & 0.12 & 0.47 & 0.10 & 0.74 & C3 & 0.48 & 0.12 & 0.42 & 0.10 & 0.73 \\
\hline C4 & 0.45 & 0.11 & 0.40 & 0.10 & 0.74 & C4 & 0.42 & 0.11 & 0.37 & 0.09 & 0.73 \\
\hline C5 & 0.39 & 0.11 & 0.35 & 0.09 & 0.73 & C5 & 0.37 & 0.11 & 0.32 & 0.09 & 0.73 \\
\hline C6 & 0.33 & 0.11 & 0.30 & 0.09 & 0.72 & C6 & 0.32 & 0.10 & 0.28 & 0.09 & 0.72 \\
\hline$C 7$ & 0.29 & 0.10 & 0.26 & 0.09 & 0.71 & $\mathrm{C7}$ & 0.28 & 0.10 & 0.25 & 0.09 & 0.71 \\
\hline C8 & 0.25 & 0.10 & 0.23 & 0.09 & 0.69 & C8 & 0.24 & 0.10 & 0.22 & 0.09 & 0.69 \\
\hline $\mathrm{C} 9$ & 0.22 & 0.10 & 0.20 & 0.09 & 0.67 & $\mathrm{C} 9$ & 0.21 & 0.10 & 0.20 & 0.09 & 0.67 \\
\hline C10 & 0.19 & 0.10 & 0.17 & 0.09 & 0.65 & C10 & 0.19 & 0.10 & 0.17 & 0.09 & 0.65 \\
\hline C11 & 0.17 & 0.09 & 0.15 & 0.08 & 0.63 & C11 & 0.17 & 0.09 & 0.16 & 0.09 & 0.63 \\
\hline
\end{tabular}

* The test of equality of means (non-parametric Kruskal-Wallis test) shows that the average of the composite indicator of GM are statistically different from the mean value of the composite indicator for conventional crops at 95\%, for any weighting combination (C1-C11) and aggregation method.

${ }^{17} \mathrm{C} 1$ implies that a weight of 1 is given to the composite indicator of pesticide use and a weight of 0 to the composite indicator of non-target key species richness, whereas $\mathrm{C} 11$ considers that a weight of 0 is given to the composite indicator of pesticide use and a weight of 1 to the composite indicator of non-target key species richness. Indicators from C1 to C11 consider a decrease of 0.1 of the weight given to the composite indicator given to pesticide use and an increase of 0.1 of the weight given to the composite indicator of non-target key species richness. 
Table 4 shows the probability of GM crops performing environmentally better than conventional crops for each combination of weights given to the composite indicators of nontarget key species richness and pesticide use. In addition, results show that the probability that GM crops outperform conventional crops from an environmental perspective is always greater than $63 \%$, regardless of the weights given to each indicator (i.e. non-target key species richness and pesticide use) and the normalisation (i.e. min-max or distance) and aggregation (i.e. additive or multiplicative) methods. We can see that the probability diminishes as the weight given to the non-target key species richness is increasing (and consequently the weight given to pesticide use is decreasing). This is a consequence that on average GM crops outperforms their conventional counterparts on pesticide use to a great extent, whereas this is not so evident for non-target key species richness.

Table 5 shows the average probability that GM crops perform environmentally better than conventional crops. In accordance with the results of Table 4, when all the individual environmental indicators are considered GM crops outperform on average conventional crops from an environmental perspective, with a probability of $70 \%$ or $78 \%$ depending on the aggregation approach.

Table 5. Overall environmental composite indicator for GM and conventional crops

\begin{tabular}{|c|c|c|c|c|c|}
\hline \multirow{2}{*}{ Overall composite indicator } & \multirow{2}{*}{$\begin{array}{l}\mathbf{G M} \\
\text { Mean }\end{array}$} & \multirow[b]{2}{*}{ Std. Dev } & \multicolumn{2}{|c|}{ Conventional } & \multirow{2}{*}{$\operatorname{Pr}(\mathbf{G M}>\text { Conv })^{\mathrm{a}}$} \\
\hline & & & Mean & Std. Dev & \\
\hline \multicolumn{6}{|l|}{ Min-max normalisation } \\
\hline Additive aggregation method & 0.50 & 0.20 & 0.44 & 0.17 & 0.77 \\
\hline Multiplicative aggregation method & 0.38 & 0.21 & 0.34 & 0.18 & 0.70 \\
\hline $\begin{array}{l}\text { Distance normalisation } \\
\text { Additive aggregation method }\end{array}$ & 0.47 & 0.18 & 0.41 & 0.16 & 0.78 \\
\hline Multiplicative aggregation method & 0.35 & 0.19 & 0.31 & 0.16 & 0.70 \\
\hline
\end{tabular}

\section{Conclusions}

The methodology developed in this paper allows researchers to make the most of published data on a particular topic. When there is information available on a particular topic, such as indicators on environmental impacts of GM and conventional crops, these can be collated and analysed allowing researchers to analyse any topic at a broad level. In this paper we collected data on environmental indicators of GM and conventional crops worldwide, allowing us to 
contribute to the open debate on which crop is less harmful from an environmental perspective. This approach can be applied to other topics such as agricultural sustainability, the efficiency of policy measures, etc.

Building composite indicators aims to establish a ranking of different options (e.g. crops, farm-types, policies, etc.) in order to elucidate which of those alternatives is the most adequate (e.g. the most sustainable crop or farm-type). Following the new approach developed in this paper, not only a ranking of alternatives can be obtained but the probability that some alternative outperforms the other(s). This information can be used to a) know up to what degree an option is better than another (i.e. knowing the level of certainty) and b) under what circumstances (i.e. what weighting combination(s)) one option is better than another. In the case of a ranking of options based on single values (e.g. average values, values calculated for a particular crop or farm, etc.) decisions are made as long as values differ and these decisions may be taken with little knowledge on the level of certainty on that decision. Hence, by using distributions instead of values overlapping amongst indicators is allowed (i.e. distributions may overlap) and not only a ranking of alternatives can be obtained, based on the average values of the distribution, but the probability that one alternative is better than another can be obtained. This can be then used to rank options differently than under a single value approach. For instance, let us have two composite indicators for GM and conventional environmental performance with values 0.30 for $\mathrm{GM}$ and 0.27 for conventional but probability of GM performing better than conventional of $51 \%$ (e.g. assuming a positive skewed distribution for GM and normal distribution with small standard deviation). Under a single value we would say that GM performs better than conventional. Under our approach there would be little evidence that one performs better than the other and we would consider them equal.

One of the main drawbacks of composite indicators is related with the weights given to each indicator. Our approach makes no assumptions concerning the importance of each indicator within the composite indicator. In fact, a set of weights that includes all the options is considered (i.e. from a weight zero assigned to indicators related with non-target key species richness to a weight equal to one, and vice versa for the pesticide use). This approach is useful in situations where we are uncertain about what specific weights should be given to each indicator used. In addition, we conducted sensitivity analysis by applying two aggregation methodologies. Regardless of the methodology used, and the weights given to indicators, results show that GM crops tend to cause lower negative environmental impacts 
than conventional crops when a number of indicators related with and pesticide use are considered. However, it is worth mentioning that the outperformance of GM crops from an environmental perspective is lower when the weight of pesticide use is lower and consequently the weight of non-target key species richness is higher. The variability in the value of the environmental composite indicator is expected since GM crops outperform conventional crops in most of the pesticide use indicators, whereas for the indicators related with non-target key species richness GM and conventional crops show relatively similar results. One of the limitations of the analysis of environmental impacts of both GM and conventional crops is related with the indicators on pesticide use. These indicators are based on the quantity of pesticides and the number of sprays, so the analysis does not take into account the toxicity of each type of pesticide (e.g. selective vs. broad spectrum pesticides) in the environment. An extension of this work based on the toxicity of pesticide use by using EIQ, would be valuable as further research.

\section{References}

Ammann, K. 2006. Effects of biotechnology on biodiversity: herbicide-tolerant and insect-resistant GM crops. Trends Biotechnol. 23, 388-394.

Andreoli, M., Tellarini, V. 2000. Farm sustainability evaluation: methodology and practice. Agr. Ecosyst. Environ. 77, 43-52.

Areal, F.J., Riesgo, L., Rodríguez-Cerezo, E. 2013a. Economic and agronomic impact of commercialised GM crops: a meta-analysis. J. Agr. Sci. 151, 7-33.

Areal, F.J., Riesgo, L., Rodríguez-Cerezo, E. 2013b. GM crops, developing countries and food security. World Agr. 3, 19-22.

Azadi, H., Ho, P. 2010. Genetically modified and organic crops in developing countries: A review of options for food security. Biotech. Adv. 28, 160-168.

Bai, Y.Y., Yan, R.H., Ye, G.Y., Huang, F., Wangila, D.S., Wang, J.J., Cheng, D.S. 2012. Field response of aboveground non-target arthropod community to transgenic Bt-Cry1 Ab rice plant residues in postharvest seasons. Transgenic Res. 21, 1023-1032.

Balog, A., Kiss, J., Szekeres, D., Szénási, A., Markó, V. 2010. Rove beetle (Coleoptera: Staphylinidae) communities in transgenic Bt (MON810) and near isogenic maize. Crop Prot. 29, 567571. 
500

501

502

503

504

505

506

507

508

509

510

511

512

513

514

515

516

517

518

519

520

521

522

523

524

525

526

527

528

529

530

531

Bannert, M. 2006. Simulation of transgenic pollen dispersal by use of different grain colour maize.

Ph.D. thesis, Swiss Federal Institute of Technology Zürich, Suiza. Available at:

http://www.agrisite.de/doc/ge_img/pollen-swiss.pdf.

Bambawale, O.M., Singh, A., Sharma, O.P., Bhosle, B.B., Lavekar, R.C., Dhandapani, A., Kanwar, V., Tanwar, R.K., Rathod, K.S., Patange, N.R., Pawar, V.M. 2004. Performance of Bt cotton (MECH162) under Integrated Pest Management in farmers' participatory field trial in Nanded district, Central India. Curr. Sci. 86, 1628-1633.

Bennett, R., Phipps, R., Strange, A., Grey, P. 2004. Environmental and human health impacts of growing genetically modified herbicide-tolerant sugar beet: a life-cycle assessment. Plant Biotechnol. J. 2(4), 273-278.

Bennett, R., Ysmael, Y., Morse, S., Shankar, B. 2004b. Reductions in insecticide use from adoption of Bt cotton in South Africa: impacts on economic performance and toxic load to the environment. J. Agr. Sci. 142, 665-674.

Bhattacharjee, R. 2009. Harnessing biotechnology for conservation and increased utilization of orphan crops. ATDF J. 6, 24-82.

Bonny, S. 2008. Genetically modified glyphosate-tolerant soybean in the USA: adoption actors, impacts and prospects. A review. Agron. Sustain. Dev. 28, 21-32.

Bowman, D.T., May, O.L., Creech, J.B. 2003. Genetic uniformity of the U.S. Upland cotton crop since the introduction of transgenic cottons. Crop Sci 43: 515-518.

Brimner, T.A., Gallivan, G.J., Stephenson, G.R. 2004. Influence of herbicide-resistant canola on the environmental impact of weed management. Pest Manag. Sci. 61(1), 47-52.

Brookes, G., Barfoot, P. 2005. GM crops: The global economic and environmental impact- the first nine years 1996-2004. AgBioforum 8, 187-196.

Brookes, G., Barfoot, P. 2008. Global impact of biotech crops: socio-economic and environmental impact-1996-2006. AgBioforum 11, 21-38.

Brookes, G., Barfoot, P. 2012. GM crops: global socio-economic and environmental impacts 19962010. PG Economics, Ltd, UK.

Brookes, G., Barfoot, P. 2013. Key environmental impacts of global genetically modified (GM) crops use 1996-2011. GM Crops Food: Biotechnol. Agric. Food Chain 4, 109-119.

Cattaneo, M.G., Yafuso, C., Schmidt, C., Huang, C.Y., Rahman, M., Olson, C., Ellers-Kirk, C., Orr, B.J., Marsh, S.E., Antillas, L., Dutilleul, P., Carrière, Y. 2006. Farm-scale evaluation of the impacts of transgenic cotton on biodiversity, pesticide use, and yield. PNAS 103, 7571-7576. 
Carpenter, J.E. 2010. Peer-reviewed surveys indicate positive impact of commercialized GM crops.

533 Nat. Biotechnol. 28, 319-321.

534 Carpenter, J.E. 2011. Impact of GM crops on biodiversity. GM Crops 2, 7-23.

535 Carrière, Y., Ellers-Kirk, C., Sisterson, M., Antilla, L., Whitlow, M., Dennehy, T., Tabashnik, B.E. 536 2003. Long-term regional suppression of pink bollworm by Bacillus thuringiensis cotton. Proc Natl 537 Acad Sci USA 100: 1519-1523.

538 Chamberlain, D.E., Freeman, S.N., Vickery, J.A. 2007. The effects of GMHT crops on bird 539 abundance in arable fields in the UK. Agr. Ecosyst. Environ.118, 350-356.

540 Champion, G.T., May, M.J., Bennett, S., Brooks, D.R., Clark, S.J., Daniels, R.E., Firbank, A.J., 541 Haughton, A.J., Hawes, C., Heard, M.S., Perry, J.N., Randle, Z., Rossall, P., Rothery, L.G., Skellern, 542 M.P., Scott, R.J., Squire, G.R., Thomas, M.R. 2003. Crop management and agronomic context of the 543 Farm-Scale Evaluations of genetically modified herbicide-tolerant crops. Philos. T. Roy. Soc. B 358, $544 \quad 1801-1818$.

545 Chib, S., Greenberg, E. 1995. Understanding the Metropolis-Hastings algorithm. Am. Stat. 49, 327546335.

547 Devos, Y., Cougnon, M., Vergucht, S., Bulcke, R., Hewsaert, G., Steurbaut, W., Reheul, D. 2008.

548 Environmental impact of herbicide regimes used with genetically modified herbicide-resistant maize. 549 Trans. Res. 17,1059-1077.

550 Devos, Y., Demont, M., Dillen, D., Reheul, M., Kaiser, M., Sanvido, O. 2009. Coexistence of 551 genetically modified (GM) and non-GM crops in the European Union. A review. Agron. Sustain. Dev. 552 29, 11-30.

553 Devos, Y., Reheul, D., Schrijver, A. 2005. The co-existence between transgenic and non-transgenic 554 maize in the European Union: a focus on pollen flow and cross-fertilization. Environ. Biosafety Res. $555 \quad 4,71-87$.

556 Dewar, A.M., May, M.J., Woiwod, I.P., Haylock, L.A., Champion, G.T., Garner, B.H., Sands, R.J., 557 Qi, A., Pidgeon, J.D. 2003. A novel approach to the use of genetically modified herbicide tolerant 558 crops for environmental benefit. Philos. T. Roy. Soc. B 270, 335-340.

559 Efron, B., Tibshirani, R. J. 1993. An introduction to the Bootstrap. NY: Chapman \& Hall/ CRC.

560 Ervin, D., Batie, S., Welsh, R., Carpentier, C.L., Fern, J.I., Richman, N.J., Shulz, M.A. 2000.

561 Transgenic crops: an environmental assessment, in Policy Studies Repors: Wallace Centre for 562 Agricultural and Environmental Policy. 
Fitt, G.P. 2008. Have Bt crops led to changes in insecticide use patterns and impacted IPM? In Romeis et al. (Eds.) Integration of insect-resistant genetically modified crops within IPM Programs, 303-328. The Netherlands: Springer.

Frison, E., Cherfas, J., Hodgkin, T. 2011. Agricultural biodiversity is essential for a sustainable improvement in food and nutrition security. Sustainability 3, 328-253.

Graef, F., Stachow, U., Werner, A., Schütte, G. 2007. Agricultural practice changes with cultivating genetically modified herbicide-tolerant oilseed rape. Agr. Syst. 94, 111-118.

Geman, S., Geman, D. 1984. Stochastic relaxation, Gibbs distributions, and the Bayesian restoration of images. IEEE T Pattern Anal 6, 721-741.

Gepts, P., Papa, R. 2003. Possible effects of trans(gene) flow from crops to the genetic diversity from landraces and wild relatives. Environ. Biosafety Res. 2, 89-113.

Gómez-Barbero, M., Berbel, J., Rodríguez-Cerezo, E. 2008. Bt corn in Spain-the performance of the EU's first GM crop. Nat. Biotechnol. 26, 384-386.

Gómez-Limón, J.A., Riesgo, L. 2009. Alternative approaches to the construction of a composite indicator of agricultural sustainability: An application to irrigated agriculture in the Duero basin in Spain. J. Environ. Manage. 90 (11), 3345-3362.

Gómez-Limón, J.A., Sánchez-Fernández, G. 2010. Empirical evaluation of agricultural sustainability using composite indicators. Ecol. Econ. 69, 1062-1075.

Gressel, J., Hanafi, A., Head, G., Marasas, W., Obilana, A.B., Ochanda, J., Souissi, T., Tzotzos, G. 2004. Major heretofore intractable biotic constrainst to African food security that may be amenable to novel biotechnological solutions. Crop Prot. 23, 661-689.

Hastings, W.K. 1970. Monte Carlo sampling methods using Markov chains and their applications. Biometrika 57, 97-109.

Hayes, K.R., Cregg, P. C., Gupta, V.V.S.R., Jessop, R., Lonsdale, W.M., Sindel, B., Stanley, J., Williams, C. K. 2004. Identifying hazards in complex ecological systems. Part 3: Hierarchical holographic model for herbicide tolerant oilseed rape. Environ. Biosafety Res. 3, 109-128.

Haughton, A.J., Champion, G.T., Hawes, C., Heard, M.S., Brooks, D.R., Bohan, D.A., Clark, S.J., Dewar, A.M., Firbank, L.G., Osborne, J.L., Perry, J.N., Rothery, P., Roy, D.B., Scott, R.J., Woiwod, I.P., Birchall, C., Skellern, M.P., Walker, J.H., Baker, P., Browne, E.L., Dewar, A.J.G., Garner, B.H., Haylock, L.A., Horne, S.L., Mason, N.S., Sands, R.J.N., Walker, M.J. 2003. Invertebrate responses to 
593

594

595

596

597

598

599

600

601

602

603

604

605

606

607

608

609

610

611

612

613

614

615

616

617

618

619

620

621

622

the management of genetically modified herbicide-tolerant and conventional spring crops. II. Withinfield epigeal and aerial arthropods. Philos. T. Roy. Soc. B 358, 1863-1877.

Hawes, C., Haughton, A.J., Osborne, J.L., Roy, D.B., Clark, S.J., Perry, J.N., Rothery, P., Bohan, D.A., Brooks, D.R., Champion, G.T., Dewar, A.M., Heard, M.S., Woiwod, I.P., Daniels, R.E., Young, M.W., Parish, A.M., Scott, R.J., Firbank, L.G., Squire, G.R. 2003. Responses of plants and invertebrate trophic groups to contrasting herbicide regimes in the Farm Scale Evaluations of genetically modified herbicide-tolerant crops. Philos. T. Roy. Soc. B 358, 1899-1913

Heard, M.S., Hawes, C., Champion, G.T., Clark, S.J., Firbank, L.G., Haughton, A.J., Parish, A.M, Perry, J.N., Rothery, P., Scott, R.J., Skellern, M.P, Squire, G.R., Hill, M.O. 2003a. Weeds in fields with contrasting conventional and genetically modified herbicide-tolerant crops. I. Effects on abundance and diversity. Philos. T. Roy. Soc. B 358, 1819-1832

Heard, M.S., Hawes, C., Champion, G.T., Clark, S.J., Firbank, L.G., Haughton, A.J., Parish, A.M., Perry, J.N., Rothery, P., Roy, D.B., Scott, R.J., Skellern, M.P., Squire, G.R., Hill, M.O. 2003b. Weeds in fields with contrasting conventional and genetically modified herbicide-tolerant crops. II. Effects on individual species. Philos. T. Roy. Soc. B 358, 1833-1846

Henry, C., Morgan, D., Weekes, R., Daniels, R., Boffey, C. 2003. Farm scale evaluations of GM crops: monitoring gene flow from GM crops to non-GM equivalent crops in the vicinity (contract reference EPG 1/5/138). Part I: Forage Maize. Final Report 2000/2003. Defra.

Hoffs, J.L., Fok, M., Vaissayre, M. 2006. Impact of Bt cotton adoption on pesticide use by smallholders: A 2-year survey in Makhatini Flats (South Africa). Crop Prot. 25, 984-988.

Huang, J., Hu, R., Rozelle, S., Pray, C. 2005. Insect-resistant GM rice in farmers' fields: Assessing productivity and health effects in China. Science 308, 688-690.

Huang, J., Rozelle, S., Pray, C., Wang, Q. 2002. Plant Biotechnol China. Science 295, 674-677.

Jacobsen, S.E., Sørensen, M., Pedersen, S.M., Weiner, J. 2013. Feeding the world: genetically modified crops versus agricultural biodiversity. Agron. Sustain. Dev. 33, 651-662.

Jansen, D.M., Stoorvogel, J.J., and Schipper, R.A. (1995). Using sustainability indicators in agricultural land use analysis: an example from Costa Rica. J. Agr. Sci. 43, 61-82.

Kahane, R., Hodgkin, T., Jaenicke, H., Hoogendoorn, C., Hermann, M., Keatinge, J.D.H., d'Arros, J., Padulosi, S., Looney, N. 2013. Agrobiodiversity for food security, health and income. Agron. Sustain. Dev. 33, 671-693. 
623 Kendall, H.W., Beachy, R., Eisner, T., Gould, F., Herdt, R., Raven, P.H., Schell, J.S., Swaminathan,

624 M.S. 1997. Bioengineering of crops. Environmental and Socially Sustainable Development Studies

625 and Monograph Series 23. Washington, DC: The World Bank.

626 Knox, O.G.G., Walker, R.L., Booth, E.J., Angus, C.H., Crossan, N., Gupta, V.V.S.R. 2012.

627 Capitalizing on deliberate, accidental, and GM-driven environmental change caused by crop 628 modification. J. Exp. Bot. 63 (2): 543-549.

629 Koop, G. 2003. Bayesian Econometrics. Chichester, West Sussex: John Wiley \&Sons Inc.

630 Kouser, S., Qaim, M. 2011. Impact of Bt cotton on pesticide poisoning in smallholder agriculture: A 631 panel data analysis. Ecol. Econ. 70, 2105-2113.

632 Kovach, J.,Petzoldt, C., Degni, J., Tette, J. 1992. A method to measure the environmental impact of 633 pesticides. New York: IPM Program, Cornell University, New York State Agricultural Experiment 634 Station Geneva, 14456. Updated annually: http://www.nysipm.cornell.edu/publications/eiq/

635 Krishna, V., Qaim, M. 2012. Bt cotton and sustainability of pesticide reductions in India. Agr. Syst. $636 \quad 107,47-55$.

637 Li, G., Feng, H., McNeil, J.N., Liu, B., Chen, P., Qiu, F. 2011. Impacts of transgenic Bt cotton on a 638 non-target pest, Apolygus lucorum (Meyer-Dür) (Hemiptera: Miridae), in northern China. Crop Prot. $63930,1573-1578$.

640 Lu, Y., Wu, K., Jiang, Y., Guo, Y., Desneux, N. 2012. Widespread adoption of Bt cotton and 641 insecticide decrease promotes biocontrol services. Nature 487, 362-367.

642 Luttrell, R.G., Jackson, R.E. 2012. Helicoverpa zea and Bt cotton in the United States. GM Crops 643 Food: Biotechnol. Agric. Food Chain 3, 213-227.

644 Mannion, A.M., Morse, S. 2012. Biotechnology in agriculture. Agronomic and environmental 645 considerations and reflections based on 15 years of GM crops. Progress in Physical Geography 36, $646 \quad 747-763$.

647 Mondelaers, K., Aertsens, J. Van Huylenbroeck, G. 2009. A meta-analysis of the differences in 648 environmental impacts between organic and conventional farming. British Food J. 111, 1098-1119.

649 Morse, S., Bennett, R., Ismael, Y. 2006. Environmental impact of genetically modified cotton in 650 South Africa. Agr. Ecosyst. Environ.117, 277-289.

651 Nardo M., Saisana, M., Saltelli, A., Tarantola, S. 2005. Tools for Composite Indicators Building. 652 Ispra: Joint Research Centre, European Commission. EUR 21682. 
653 National Research Council 2010.The impact of genetically engineered crops on farm sustainability in 654 the United States. Washington, DC: The National Academies Press.

655 Nelson, G.C., Bullock, D.S. 2003. Simulating a relative environmental effect of glyphosate-resistant 656 soybeans. Ecol. Econ. 45, 189-202.

657 OECD. 2008. Handbook on constructing composite indicators. Methodology and user guide. Paris: 658 OECD.

659 Owen, M.D.K., Zelaya, I,A., 2005. Herbicide-resistant crops and weed resistance to herbicides. Pest 660 Manag. Sci. 6, 301-311.

661 Padulosi, S., Heywood, V., Hunter, D., Jarvis, A. 2011. Underutilised species and climate change: 662 current status and outlook. In Yadav SS, Reden RJ, Hatfield JL, Lotze-Campen H, Hall AE (eds.) 663 Crop adaptation to climate change. Wiley, New York, 507-521.

664 Paluadelmás, M., Peñas, G., Melé, E., Serra, J., Salvia, J., Pla, M., Nadal, A., Messeguer, J. 2009. 665 Effect of volunteers on maize gene flow. Trans. Res. 18, 583-594.

666 Park J.R., McFarlane I., Phipps R., Ceddia M.G. 2011. The impact of the EU regulatory constraint of 667 transgenic crops on farm income. New Biotechnol. 28, 4, 396-406.

668 Pray, C.E., Huang, J., Hu, R., Rozelle, S. 2002. Five years of Bt cotton in China - the benefits 669 continue. Plant J. 31, 423-430.

670 Pemsl, D., Waibel, H., Orphal, J. 2004. A methodology to assess the profitability of Bt-cotton: case 671 study results from the state of Karnataka, India. Crop Prot. 23, 1249-1257.

672 Pirazzoli, C., Castellini, A. 2000. Application of a model for evaluating the environmental 673 sustainability of cultures in hill and mountain areas. The case of berries and fruit chestnut in Northern 674 Italy. Agr. Econ. Rev. 1, 57-70.

675 Qaim, M. 2009. The economics of genetically modified crops. Annu. Rev. Resour. Econ., 1, 665-694.

676 Qaim, M., de Janvry, A. 2005. Bt cotton and pesticide use in Argentina: economic and environmental 677 effects. Environ. Dev. Econ. 10, 179-200.

678 Qaim, M., Traxler, G. 2005. Roundup Ready soybeans in Argentina: farm level and aggregate welfare 679 effects. Agr. Econ. 32, 73-86.

680 Qaim, M., Zilberman, D. 2003. Yield effects of genetically modified crops in developing Countries. 681 Science 299, 900-902. 
684 Qiu, H.J., Zhu, W.B., Wang, H.B., Cheng, X. 2007. Analysis and design of agricultural sustainability indicators system. Agr. Sci. China 6, 475-486. methods for assessing the impacts of Bt-maize MON810 cultivation and pyrethroid insecticide use on Auchenorrhyncha (planthoppers and leafhoppers). Agr. Forest Entomol. 10, 331-339. MON88017 in comparison to three conventional lines on Trigonotylus caelestialium (Kirkaldy) (Heteroptera: Miridae) field densities. Transgenic. Res. 18, 203-214.

Riesgo, L., Areal, F.J., Sanvido, O., Rodríguez-Cerezo, E. 2010. Distances needed to limit crossfertilization between GM and conventional maize in Europe. Nature Biotech. 28, 780-782. sustainable agricultural practice. Ecol. Econ. 39, 463-478. regimes in the Farm Scale Evaluations of genetically modified herbicide-tolerant crops. Philos. T. Roy. Soc. B 358, 1879-1898.

701 Sands, G.R., Podmore, T.H. 2000. A generalized environmental sustainability index for agricultural systems. Agr. Ecosyst. Environ.79, 29-41.

Sanvido, O., Romeis, J., Bigler, F. 2007. Ecological impacts of genetically modified crops: ten years of field research and comercial cultivation. Adv. Biochem. Eng. Biotechnol. 107, 235-278.

Shaner, D.L. 2000. The impact of glyphosate-tolerant crops on the use of other herbicides and on resistance management. Pest Manag. Sci. 56, 320-326. South Africa. Appl. Econ. 40, 2489-2500. 
711 Sisterson, M.S., Biggs, R.W., Manhardt, N.M., Carrière, Y., Dennehy, T.J., Tabashnik, B.E. 2007.

712 Effects of transgenic Bt cotton on insecticide use and abundance of two generalist predators. Entomol.

713 Exp. Appl. 124, 305-311.

714 Smyth, S.J., Gusta, M., Belcher, K., Phillips, P.W.B., Castle, D. 2011. Environmental impacts of

715 herbicide tolerant canola production in Western Canada. Agr. Syst. 104, 403-410.

716 Sneller, C.H. 2003. Impact of transgenic genotypes and subdivision on diversity within elite North

717 American soybean germplasm. Crop Sci. 43, 409-414.

718 Squire, G.R., Brooks, D.R, Bohan, D.A., Champion, G.T., Daniels, R.E., Haughton, A.J., Hawes, C.,

719 Heard, M.S., Hill, M.O., May, M.J., Osborne, J.L., Perry, J.N., Roy, D.B., Woiwod, I.P., Firbank,

720 L.G. 2003. On the rationale and interpretation of the Farm Scale Evaluations of genetically modified

721 herbicide-tolerant crops. Philos. T. Roy. Soc. B 358, 1779-1799.

722 Stone, G.D. 2011. Field versus farm in Warangal: Bt cotton, higher yields, and larger questions.

723 World Dev. 39, 387-398.

724

Sydorovych, O., Marra, M.C. 2007. A genetically engineered crop's impact on pesticide use: a revealed-preference index approach. J. Agr. Resource Econ. 32, 476-491.

726

Traxler, G., Godoy-Avila, S., Falck-Zepeda, J., Espinoza-Arellano, J.J. 2003. Transgenic cotton in Mexico: economic and environmental impacts of the first generation biotechnologies. In: N. Kalaitzandonakes (Ed.) The Economic and environmental impacts of agbiotech: a global perspective, 183-202. New York: Kluwer Academic Publishers.

730

Tuomiso, H.L., Hodge, I.D., Riordan, P. Macdonald, D.W. 2012. Does organic farming reduce environmental impacts? A meta-analysis of European research. J. Environ. Manag. 112, 309-320. Development and application of a multi-attribute sustainability function for Dutch dairy farming systems. Ecol. Econ. 57, 640-658.

735 Wan, P., Huang, Y., Tabashnik, B.E., Huang, M. y Wu, K. 2012. The Halo Effect: Suppression of 736 Pink Bollworm on Non-Bt Cotton by Bt Cotton in China. PLoS One 7: e42004.

Wesseler, J., Scatasta, S., El Hadji, F. 2011. The Environmental Benefits and Costs of Genetically Modified (GM) Crops. In: Beladi, H and Choi, EK. (Eds.), Frontiers of Economics and Globalisation. Emerald. plants. Science 290, 2088-2093. 
742 Wossink, A., Denaux, Z.S. 2006. Environmental and cost efficiency of pesticide use in transgenic and 743 conventional cotton production. Agr. Syst. 90, 312-328.

744 Zeilinger, A.R., Andow, D.A., Zwahlen, C., Stotzky, G. 2010. Earthworm populations in a northern

745 US cornbelt soil are not affected by long-term cultivation of Bt maiaze expressing Cry1 Ab and

746 Cry3Bb1 proteins. Soil Biol. Biochem. 42, 1284-1292.

747 Zhao, J.H., Ho, P., Azadi, H. 2011. Benefits of Bt cotton counterbalanced by secondary pests?

748 Perceptions of ecological change in China. Environ. Monit. Assess. 173, 985-994.

749

750

751

752 
754 Table A1- Dataset of non-target species richness for GM and conventional crops

\begin{tabular}{|c|c|c|c|c|c|c|c|c|}
\hline Scientific Reference & Year & Country & Non- Target Species & $\begin{array}{l}\text { Trait// } \\
\text { Crop } \\
\end{array}$ & $\begin{array}{r}\text { Mean } \\
\text { GM } \\
\end{array}$ & $\begin{array}{l}\text { Mean } \\
\text { Conv. }\end{array}$ & $\begin{array}{c}\text { No. } \\
\text { observations }\end{array}$ & Units \\
\hline \multirow[t]{5}{*}{ Rauschen et al. (2008) } & 2003 & Germany & Auchenorrhyncha (arthropods) & Bt maize & 116.9 & 116.9 & 192 & No. of individuals \\
\hline & 2004 & Germany & Auchenorrhyncha (arthropods) & Bt maize & 1.5 & 1.7 & 29 & No. of individuals \\
\hline & 2005 & Germany & Auchenorrhyncha (arthropods) & Bt maize & 2 & 2.9 & 45 & No. of individuals \\
\hline & 2006 & Germany & Auchenorrhyncha (arthropods) & Bt maize & 2.3 & 2.1 & 42 & No. of individuals \\
\hline & 2007 & Germany & Auchenorrhyncha (arthropods) & Bt maize & 0.1 & 0 & 2 & No. of individuals \\
\hline \multirow[t]{11}{*}{ Rauschen et al. (2009) } & 2005 & Germany & Trygonotylus caelestialium (arthropods) & Bt maize & 16.63 & 17.75 & 8 & No. of individuals \\
\hline & 2005 & Germany & Trygonotylus caelestialium (arthropods) & Bt maize & 3.25 & 1.38 & 8 & No. of individuals \\
\hline & 2006 & Germany & Trygonotylus caelestialium (arthropods) & Bt maize & 31.13 & 20.88 & 8 & No. of individuals \\
\hline & 2006 & Germany & Trygonotylus caelestialium (arthropods) & Bt maize & 7.38 & 1.5 & 8 & No. of individuals \\
\hline & 2006 & Germany & Trygonotylus caelestialium (arthropods) & Bt maize & 1.13 & 1 & 8 & No. of individuals \\
\hline & 2007 & Germany & Trygonotylus caelestialium (arthropods) & Bt maize & 7.38 & 6.63 & 8 & No. of individuals \\
\hline & 2007 & Germany & Trygonotylus caelestialium (arthropods) & Bt maize & 1.5 & 0.63 & 8 & No. of individuals \\
\hline & 2007 & Germany & Trygonotylus caelestialium (arthropods) & Bt maize & 0.38 & 0.5 & 8 & No. of individuals \\
\hline & 2006 & Germany & Trygonotylus caelestialium (arthropods) & Bt maize & 0.13 & 0.25 & 8 & No. of individuals \\
\hline & 2006 & Germany & Trygonotylus caelestialium (arthropods) & Bt maize & 3.38 & 10.75 & 8 & No. of individuals \\
\hline & 2006 & Germany & Trygonotylus caelestialium (arthropods) & Bt maize & 4.75 & 3.75 & 8 & No. of individuals \\
\hline \multirow[t]{3}{*}{ Rauschen et al. (2009) } & 2007 & Germany & Trygonotylus caelestialium (arthropods) & Bt maize & 0.38 & 0.5 & 8 & No. of individuals \\
\hline & 2007 & Germany & Trygonotylus caelestialium (arthropods) & Bt maize & 5.63 & 3.25 & 8 & No. of individuals \\
\hline & 2007 & Germany & Trygonotylus caelestialium (arthropods) & Bt maize & 0.38 & 1.25 & 8 & No. of individuals \\
\hline \multirow[t]{3}{*}{ Deward et al. (2003) } & 1999 & UK & $\begin{array}{c}\text { Carabids+staogtkubuds+spiders } \\
\text { (arthropods) }\end{array}$ & $\begin{array}{l}\text { HT sugar } \\
\text { beet }\end{array}$ & 2536 & 2459 & 4 & No. of individuals \\
\hline & 1999 & UK & $\begin{array}{l}\text { Carabids+staogtkubuds+spiders } \\
\text { (arthropods) }\end{array}$ & $\begin{array}{l}\text { HT sugar } \\
\text { beet }\end{array}$ & 2525 & 2493 & 4 & No. of individuals \\
\hline & 2000 & UK & $\begin{array}{c}\text { Carabids+staogtkubuds+spiders } \\
\text { (arthropods) }\end{array}$ & $\begin{array}{l}\text { HT sugar } \\
\text { beet }\end{array}$ & 3690 & 3403 & 4 & No. of individuals \\
\hline
\end{tabular}




\begin{tabular}{|c|c|c|c|c|c|c|c|c|}
\hline Scientific Reference & Year & Country & Non- Target Species & $\begin{array}{l}\text { Trait/ } \\
\text { Crop }\end{array}$ & $\begin{array}{r}\text { Mean } \\
\text { GM }\end{array}$ & $\begin{array}{l}\text { Mean } \\
\text { Conv. }\end{array}$ & $\begin{array}{c}\text { No. } \\
\text { observations }\end{array}$ & Units \\
\hline Deward et al. (2003) & 2000 & UK & $\begin{array}{c}\text { Carabids+staogtkubuds+spiders } \\
\text { (arthropods) }\end{array}$ & $\begin{array}{l}\text { HT sugar } \\
\text { beet }\end{array}$ & 796 & 894 & 4 & No. of individuals \\
\hline \multirow[t]{4}{*}{ Bai et al. (2012) } & 2007 & China & Arthropods & Bt rice & 1028.6 & 972.3 & 2 & No. of individuals \\
\hline & 2008 & China & Arthropods & $\mathrm{Bt}$ rice & 4503 & 4883.7 & 2 & No. of individuals \\
\hline & 2007 & China & Arthropods & $\mathrm{Bt}$ rice & 1169.7 & 972.3 & 2 & No. of individuals \\
\hline & 2008 & China & Arthropods & $\mathrm{Bt}$ rice & 5084 & 4883.7 & 2 & No. of individuals \\
\hline \multirow[t]{8}{*}{ Haughton et al. (2003) } & 2002 & UK & Heteroptera (arthropods) & HT beet & 2.8 & 5.18 & 48 & No. of individuals \\
\hline & 2002 & $\mathrm{UK}$ & Heteroptera (arthropods) & HT maize & 3.14 & 3.53 & 42 & No. of individuals \\
\hline & 2002 & UK & Heteroptera (arthropods) & HT oilseed & 3.82 & 5.05 & 41 & No. of individuals \\
\hline & 2002 & UK & Collembola (arthropods) & HT beet & 66.75 & 59 & 64 & No. of individuals \\
\hline & 2002 & UK & Collembola (arthropods) & HT maize & 119.01 & 75.81 & 57 & No. of individuals \\
\hline & 2002 & UK & Collembola (arthropods) & HT oilseed & 125.36 & 118.3 & 64 & No. of individuals \\
\hline & 2002 & UK & Araneae (arthropods) & HT beet & 8.73 & 8.68 & 64 & No. of individuals \\
\hline & 2002 & UK & Araneae (arthropods) & HT maize & 6.11 & 6.5 & 55 & No. of individuals \\
\hline \multirow[t]{10}{*}{ Haughton et al. (2003) } & 2002 & UK & Araneae (arthropods) & HT oilseed & 6.93 & 8.5 & 64 & No. of individuals \\
\hline & 2002 & UK & Bees (arthropods) & HT beet & 1.55 & 3.62 & 20 & No. of individuals \\
\hline & 2002 & UK & Bees (arthropods) & HT maize & 2.09 & 1.14 & 15 & No. of individuals \\
\hline & 2002 & UK & Bees (arthropods) & HT oilseed & 36.52 & 44.28 & 62 & No. of individuals \\
\hline & 2002 & $\mathrm{UK}$ & Butterflies (arthropods) & HT beet & 3.88 & 5.65 & 58 & No. of individuals \\
\hline & 2002 & UK & Butterflies (arthropods) & HT maize & 3.74 & 3.28 & 35 & No. of individuals \\
\hline & 2002 & UK & Butterflies (arthropods) & HT oilseed & 12.41 & 16.17 & 65 & No. of individuals \\
\hline & 2002 & UK & Carabidae (arthropods) & HT beet & 3.84 & 4.26 & 57 & No. of individuals \\
\hline & 2002 & UK & Carabidae (arthropods) & HT maize & 4.13 & 3.28 & 43 & No. of individuals \\
\hline & 2002 & UK & Carabidae (arthropods) & HT oilseed & 3.55 & 3.5 & 54 & No. of individuals \\
\hline \multirow[t]{4}{*}{ Balog et al. (2010) } & 2001 & Hungary & Rove beetles (arthropods) & Bt maize & 2 & 2 & 12 & No. of individuals \\
\hline & 2001 & Hungary & Rove beetles (arthropods) & Bt maize & 6 & 4 & 12 & No. of individuals \\
\hline & 2001 & Hungary & Rove beetles (arthropods) & Bt maize & 1 & 1 & 12 & No. of individuals \\
\hline & 2001 & Hungary & Rove beetles (arthropods) & Bt maize & 24 & 12 & 12 & No. of individuals \\
\hline
\end{tabular}




\begin{tabular}{|c|c|c|c|c|c|c|c|c|}
\hline Scientific Reference & Year & Country & Non- Target Species & $\begin{array}{l}\text { Trait/ } \\
\text { Crop }\end{array}$ & $\begin{array}{r}\text { Mean } \\
\text { GM } \\
\end{array}$ & $\begin{array}{l}\text { Mean } \\
\text { Conv. }\end{array}$ & $\begin{array}{c}\text { No. } \\
\text { observations }\end{array}$ & Units \\
\hline \multirow[t]{26}{*}{ Balog et al. (2010) } & 2001 & Hungary & Rove beetles (arthropods) & Bt maize & 1 & 11 & 12 & No. of individuals \\
\hline & 2002 & Hungary & Rove beetles (arthropods) & Bt maize & 21 & 12 & 12 & No. of individuals \\
\hline & 2002 & Hungary & Rove beetles (arthropods) & Bt maize & 7 & 14 & 12 & No. of individuals \\
\hline & 2002 & Hungary & Rove beetles (arthropods) & Bt maize & 4 & 5 & 12 & No. of individuals \\
\hline & 2002 & Hungary & Rove beetles (arthropods) & Bt maize & 7 & 7 & 12 & No. of individuals \\
\hline & 2002 & Hungary & Rove beetles (arthropods) & Bt maize & 7 & 4 & 12 & No. of individuals \\
\hline & 2002 & Hungary & Rove beetles (arthropods) & Bt maize & 3 & 2 & 12 & No. of individuals \\
\hline & 2002 & Hungary & Rove beetles (arthropods) & Bt maize & 1 & 6 & 12 & No. of individuals \\
\hline & 2002 & Hungary & Rove beetles (arthropods) & Bt maize & 1 & 4 & 12 & No. of individuals \\
\hline & 2002 & Hungary & Rove beetles (arthropods) & Bt maize & 2 & 7 & 12 & No. of individuals \\
\hline & 2002 & Hungary & Rove beetles (arthropods) & Bt maize & 1 & 4 & 12 & No. of individuals \\
\hline & 2002 & Hungary & Rove beetles (arthropods) & Bt maize & 17 & 29 & 12 & No. of individuals \\
\hline & 2002 & Hungary & Rove beetles (arthropods) & Bt maize & 14 & 6 & 12 & No. of individuals \\
\hline & 2002 & Hungary & Rove beetles (arthropods) & Bt maize & 2 & 1 & 12 & No. of individuals \\
\hline & 2003 & Hungary & Rove beetles (arthropods) & Bt maize & 25 & 3 & 12 & No. of individuals \\
\hline & 2003 & Hungary & Rove beetles (arthropods) & Bt maize & 13 & 11 & 12 & No. of individuals \\
\hline & 2003 & Hungary & Rove beetles (arthropods) & Bt maize & 1 & 1 & 12 & No. of individuals \\
\hline & 2003 & Hungary & Rove beetles (arthropods) & Bt maize & 12 & 8 & 12 & No. of individuals \\
\hline & 2003 & Hungary & Rove beetles (arthropods) & Bt maize & 7 & 7 & 12 & No. of individuals \\
\hline & 2003 & Hungary & Rove beetles (arthropods) & Bt maize & 1 & 7 & 12 & No. of individuals \\
\hline & 2003 & Hungary & Rove beetles (arthropods) & Bt maize & 6 & 3 & 12 & No. of individuals \\
\hline & 2003 & Hungary & Rove beetles (arthropods) & Bt maize & 1 & 3 & 12 & No. of individuals \\
\hline & 2003 & Hungary & Rove beetles (arthropods) & Bt maize & 456 & 646 & 12 & No. of individuals \\
\hline & 2003 & Hungary & Rove beetles (arthropods) & Bt maize & 5 & 5 & 12 & No. of individuals \\
\hline & 2003 & Hungary & Rove beetles (arthropods) & Bt maize & 13 & 18 & 12 & No. of individuals \\
\hline & 2003 & Hungary & Rove beetles (arthropods) & Bt maize & 6 & 4 & 12 & No. of individuals \\
\hline \multirow[t]{2}{*}{ Chamberlain et al. (2007) } & 2001 & UK & Red-legged partridge (Birds) & HT beet & 30 & 12.52 & 8 & No. of individuals \\
\hline & 2001 & UK & Skylark (Birds) & HT beet & 49.995 & 47.52 & 11 & No. of individuals \\
\hline
\end{tabular}




\begin{tabular}{|c|c|c|c|c|c|c|c|c|}
\hline Scientific Reference & Year & Country & Non- Target Species & $\begin{array}{l}\text { Trait/ } \\
\text { Crop }\end{array}$ & $\begin{array}{r}\text { Mean } \\
\text { GM } \\
\end{array}$ & $\begin{array}{l}\text { Mean } \\
\text { Conv. }\end{array}$ & $\begin{array}{c}\text { No. } \\
\text { observations }\end{array}$ & Units \\
\hline \multirow[t]{12}{*}{ Chamberlain et al. (2007) } & 2001 & UK & Blackbird (Birds) & HT beet & 24.99 & 22.5 & 6 & No. of individuals \\
\hline & 2001 & UK & Thrushes (Birds) & HT beet & 27.51 & 22.5 & 6 & No. of individuals \\
\hline & 2001 & UK & Granivores (Birds) & HT beet & 64.2 & 52.5 & 15 & No. of individuals \\
\hline & 2001 & UK & Red-legged partridge (Birds) & HT beet & 61.11 & 27.23 & 14 & No. of individuals \\
\hline & 2001 & UK & Skylark (Birds) & HT beet & 42.49 & 53.76 & 14 & No. of individuals \\
\hline & 2001 & UK & Dunnock (Birds) & HT beet & 5 & 11.25 & 5 & No. of individuals \\
\hline & 2001 & UK & Blackbird (Birds) & HT beet & 33.825 & 30.91 & 11 & No. of individuals \\
\hline & 2001 & UK & Yellowhammer (Birds) & HT beet & 2.925 & 12.675 & 5 & No. of individuals \\
\hline & 2001 & UK & Trushes (Birds) & HT beet & 35.475 & 35.09 & 11 & No. of individuals \\
\hline & 2001 & $\mathrm{UK}$ & Granivores (Birds) & HT beet & 47.88 & 81.45 & 18 & No. of individuals \\
\hline & 2001 & UK & Granivores (Birds) & HT maize & 5.82 & 31.68 & 6 & No. of individuals \\
\hline & 2001 & UK & Granivores (Birds) & HT oilseed & 43.68 & 31.83 & 6 & No. of individuals \\
\hline \multirow[t]{8}{*}{ Li et al. (2011) } & 2007 & China & Hemiptera (arthropods) & Bt cotton & 3.2 & 3.1 & 3 & No. indiv /100 plants \\
\hline & 2007 & China & Hemiptera (arthropods) & Bt cotton & 3.3 & 3.4 & 3 & No. indiv /100 plants \\
\hline & 2008 & China & Hemiptera (arthropods) & Bt cotton & 9.6 & 9.8 & 3 & No. indiv /100 plants \\
\hline & 2008 & China & Hemiptera (arthropods) & Bt cotton & 8.5 & 7.1 & 3 & No. indiv /100 plants \\
\hline & 2009 & China & Hemiptera (arthropods) & Bt cotton & 3.4 & 2.6 & 3 & No. indiv /100 plants \\
\hline & 2009 & China & Hemiptera (arthropods) & Bt cotton & 2.1 & 2.8 & 3 & No. indiv /100 plants \\
\hline & 2010 & China & Hemiptera (arthropods) & Bt cotton & 2.5 & 2.3 & 3 & No. indiv /100 plants \\
\hline & 2010 & China & Hemiptera (arthropods) & Bt cotton & 2.5 & 2.5 & 3 & No. indiv /100 plants \\
\hline \multirow[t]{7}{*}{ Lu et al. (2012) } & 2001 & China & Ladybirds+lacewings+spiders (arthropods) & Bt cotton & 19.63 & 18.5 & 360 & No. indiv /100 plants \\
\hline & 2002 & China & Ladybirds+lacewings+spiders (arthropods) & Bt cotton & 16.04 & 17.06 & 360 & No. indiv /100 plants \\
\hline & 2003 & China & Ladybirds+lacewings+spiders (arthropods) & Bt cotton & 61.13 & 63.93 & 360 & No. indiv /100 plants \\
\hline & 2004 & China & Ladybirds+lacewings+spiders (arthropods) & Bt cotton & 27.93 & 28.41 & 360 & No. indiv /100 plants \\
\hline & 2005 & China & Ladybirds+lacewings+spiders (arthropods) & Bt cotton & 16.07 & 16.65 & 360 & No. indiv /100 plants \\
\hline & 2006 & China & Ladybirds+lacewings+spiders (arthropods) & Bt cotton & 24.91 & 24.93 & 360 & No. indiv /100 plants \\
\hline & 2007 & China & Ladybirds+lacewings+spiders (arthropods) & Bt cotton & 23.67 & 22.35 & 360 & No. indiv /100 plants \\
\hline
\end{tabular}




\begin{tabular}{|c|c|c|c|c|c|c|c|c|}
\hline Scientific Reference & Year & Country & Non- Target Species & $\begin{array}{l}\text { Trait/ } \\
\text { Crop }\end{array}$ & $\begin{array}{r}\text { Mean } \\
\text { GM }\end{array}$ & $\begin{array}{l}\text { Mean } \\
\text { Conv. }\end{array}$ & $\begin{array}{c}\text { No. } \\
\text { observations }\end{array}$ & Units \\
\hline \multirow[t]{15}{*}{ Lu et al. (2012) } & 2008 & China & Ladybirds+lacewings+spiders (arthropods) & Bt cotton & 35.13 & 36.44 & 360 & No. indiv /100 plants \\
\hline & 2009 & China & Ladybirds+lacewings+spiders (arthropods) & Bt cotton & 20.37 & 19.03 & 360 & No. indiv /100 plants \\
\hline & 2010 & China & Ladybirds+lacewings+spiders (arthropods) & Bt cotton & 39.89 & 42.7 & 360 & No. indiv /100 plants \\
\hline & 2011 & China & Ladybirds+lacewings+spiders (arthropods) & Bt cotton & 14.57 & 15.3 & 360 & No. indiv /100 plants \\
\hline & 2001 & China & Aphids (arthropods) & Bt cotton & 152.81 & 90.67 & 240 & No. indiv /100 plants \\
\hline & 2002 & China & Aphids (arthropods) & Bt cotton & 1961.49 & 821.41 & 240 & No. indiv /100 plants \\
\hline & 2003 & China & Aphids (arthropods) & Bt cotton & 1675.47 & 812.32 & 240 & No. indiv /100 plants \\
\hline & 2004 & China & Aphids (arthropods) & Bt cotton & 852 & 780.85 & 240 & No. indiv /100 plants \\
\hline & 2005 & China & Aphids (arthropods) & Bt cotton & 1344.12 & 1292.85 & 240 & No. indiv /100 plants \\
\hline & 2006 & China & Aphids (arthropods) & Bt cotton & 1804.89 & 1665.39 & 240 & No. indiv /100 plants \\
\hline & 2007 & China & Aphids (arthropods) & Bt cotton & 443.38 & 386.11 & 240 & No. indiv /100 plants \\
\hline & 2008 & China & Aphids (arthropods) & Bt cotton & 810.39 & 732.76 & 240 & No. indiv /100 plants \\
\hline & 2009 & China & Aphids (arthropods) & Bt cotton & 3214.58 & 3291.07 & 240 & No. of individuals /100 \\
\hline & 2010 & China & Aphids (arthropods) & Bt cotton & 1550.33 & 1427.44 & 240 & No. of individuals /100 \\
\hline & 2011 & China & Aphids (arthropods) & Bt cotton & 3041.88 & 3067.78 & 240 & No. of individuals /100 \\
\hline \multirow[t]{13}{*}{ Zeilinger et al. (2010) } & 2005 & USA & Earthworms & Bt maize & 0.51 & 0 & 24 & $\mathrm{mg} / \mathrm{m}^{2}$ \\
\hline & 2005 & USA & Earthworms & Bt maize & 1.09 & 1.08 & 24 & $\mathrm{mg} / \mathrm{m}^{2}$ \\
\hline & 2005 & USA & Earthworms & Bt maize & 0 & 0.5 & 24 & $\mathrm{mg} / \mathrm{m}^{2}$ \\
\hline & 2005 & USA & Earthworms & Bt maize & 1.75 & 1.08 & 24 & $\mathrm{mg} / \mathrm{m}^{2}$ \\
\hline & 2005 & USA & Earthworms & Bt maize & 0.5 & 0 & 24 & $\mathrm{mg} / \mathrm{m}^{2}$ \\
\hline & 2005 & USA & Earthworms & Bt maize & 0.5 & 0.5 & 24 & $\mathrm{mg} / \mathrm{m}^{2}$ \\
\hline & 2005 & USA & Earthworms & Bt maize & 38.1 & 27.1 & 24 & $\mathrm{mg} / \mathrm{m}^{2}$ \\
\hline & 2005 & USA & Earthworms & Bt maize & 21.9 & 45.9 & 24 & $\mathrm{mg} / \mathrm{m}^{2}$ \\
\hline & 2005 & USA & Earthworms & Bt maize & 24.6 & 90.4 & 24 & $\mathrm{mg} / \mathrm{m}^{2}$ \\
\hline & 2005 & USA & Earthworms & Bt maize & 112 & 31.9 & 24 & $\mathrm{mg} / \mathrm{m}^{2}$ \\
\hline & 2005 & USA & Earthworms & Bt maize & 107 & 71.1 & 24 & $\mathrm{mg} / \mathrm{m}^{2}$ \\
\hline & 2005 & USA & Earthworms & Bt maize & 124 & 97.8 & 24 & $\mathrm{mg} / \mathrm{m}^{2}$ \\
\hline & 2005 & USA & Earthworms & Bt maize & 0 & 1.1 & 24 & $\mathrm{mg} / \mathrm{m}^{2}$ \\
\hline
\end{tabular}




\begin{tabular}{|c|c|c|c|c|c|c|c|c|}
\hline Scientific Reference & Year & Country & Non- Target Species & $\begin{array}{l}\text { Trait/ } \\
\text { Crop }\end{array}$ & $\begin{array}{r}\text { Mean } \\
\text { GM }\end{array}$ & $\begin{array}{l}\text { Mean } \\
\text { Conv. }\end{array}$ & $\begin{array}{c}\text { No. } \\
\text { observations }\end{array}$ & Units \\
\hline \multirow[t]{17}{*}{ Zeilinger et al. (2010) } & 2005 & USA & Earthworms & Bt maize & 0 & 0.51 & 24 & $\mathrm{mg} / \mathrm{m}^{2}$ \\
\hline & 2005 & USA & Earthworms & Bt maize & 0 & 1.77 & 24 & $\mathrm{mg} / \mathrm{m}^{2}$ \\
\hline & 2005 & USA & Earthworms & Bt maize & 3.48 & 1.1 & 24 & $\mathrm{mg} / \mathrm{m}^{2}$ \\
\hline & 2005 & USA & Earthworms & Bt maize & 1.09 & 0.51 & 24 & $\mathrm{mg} / \mathrm{m}^{2}$ \\
\hline & 2005 & USA & Earthworms & Bt maize & 0.51 & 1.77 & 24 & $\mathrm{mg} / \mathrm{m}^{2}$ \\
\hline & 2005 & USA & Earthworms & Bt maize & 1.42 & 1.42 & 24 & $\mathrm{mg} / \mathrm{m}^{2}$ \\
\hline & 2005 & USA & Earthworms & Bt maize & 0.25 & 0.65 & 24 & $\mathrm{mg} / \mathrm{m}^{2}$ \\
\hline & 2005 & USA & Earthworms & Bt maize & 1.1 & 1.25 & 24 & $\mathrm{mg} / \mathrm{m}^{2}$ \\
\hline & 2005 & USA & Earthworms & Bt maize & 40.6 & 22.7 & 24 & $\mathrm{mg} / \mathrm{m}^{2}$ \\
\hline & 2005 & USA & Earthworms & Bt maize & 11 & 19.9 & 24 & $\mathrm{mg} / \mathrm{m}^{2}$ \\
\hline & 2005 & USA & Earthworms & Bt maize & 7.05 & 15.2 & 24 & $\mathrm{mg} / \mathrm{m}^{2}$ \\
\hline & 2006 & USA & Earthworms & Bt maize & 38.1 & 34.6 & 24 & $\mathrm{mg} / \mathrm{m}^{2}$ \\
\hline & 2006 & USA & Earthworms & Bt maize & 22.6 & 26.3 & 24 & $\mathrm{mg} / \mathrm{m}^{2}$ \\
\hline & 2006 & USA & Earthworms & Bt maize & 47.2 & 74.1 & 24 & $\mathrm{mg} / \mathrm{m}^{2}$ \\
\hline & 2006 & USA & Earthworms & Bt maize & 70.2 & 73.3 & 24 & $\mathrm{mg} / \mathrm{m}^{2}$ \\
\hline & 2006 & USA & Earthworms & Bt maize & 32.6 & 29.9 & 24 & $\mathrm{mg} / \mathrm{m}^{2}$ \\
\hline & 2006 & USA & Earthworms & Bt maize & 87.2 & 41.9 & 24 & $\mathrm{mg} / \mathrm{m}^{2}$ \\
\hline
\end{tabular}


Table A2- Dataset of pesticide use for GM and conventional crops

\begin{tabular}{|c|c|c|c|c|c|c|c|}
\hline Scientific Reference & Year & Country & Trait/ Crop & $\begin{array}{r}\text { Mean } \\
\text { GM } \\
\end{array}$ & $\begin{array}{l}\text { Mean } \\
\text { Conv. }\end{array}$ & $\begin{array}{c}\text { No. } \\
\text { observations }\end{array}$ & Units \\
\hline \multirow[t]{2}{*}{ Sisterson et al. (2007) } & 2004 & USA & Bt cotton & 0.23 & 1.63 & 8 & No. of sprays \\
\hline & 2004 & USA & Bt cotton & 1.08 & 2.63 & 8 & No. of sprays \\
\hline \multirow[t]{2}{*}{ Qaim and de Janvry (2005) } & 2000 & Argentina & Bt maize & 2.14 & 3.74 & 29 & No. of sprays \\
\hline & 2001 & Argentina & Bt maize & 2.84 & 3.7 & 73 & No. of sprays \\
\hline \multirow[t]{4}{*}{ Cattaneo et al. (2006) } & 2002 & USA & Bt cotton & 3.4 & 6.6 & 21 & No. of sprays \\
\hline & 2003 & USA & Bt cotton & 5.1 & 6.8 & 21 & No. of sprays \\
\hline & 2002 & USA & Stacked cotton & 2.8 & 6.6 & 20 & No. of sprays \\
\hline & 2003 & USA & Stacked cotton & 4.7 & 6.8 & 20 & No. of sprays \\
\hline Huang et al. (2005) & 2003 & China & GM rice & 0.5 & 3.7 & 123 & No. of sprays \\
\hline Qaim and Traxler (2005) & 2001 & Argentina & HT soybean & 2.3 & 1.97 & 59 & No. of sprays \\
\hline Qaim and Zilberman (2003) & 2001 & India & Bt cotton & 4.19 & 7.19 & 157 & No. of sprays \\
\hline Huang et al. (2002) & 1999 & China & Bt cotton & 6.6 & 19.8 & 45 & No. of sprays \\
\hline Hofs et al. (2006) & 2003 & South Africa & Bt cotton & 2.3 & 2.9 & 10 & No. of sprays \\
\hline Qaim et al. (2006) & 2003 & India & Bt cotton & 4.18 & 6.79 & 133 & No. of sprays \\
\hline \multirow[t]{3}{*}{ Champion et al. (2003) } & 2001 & UK & HT sugar beet & 1.65 & 3.65 & 20 & No. of sprays \\
\hline & 2001 & UK & HT maize & 1.18 & 1.32 & 29 & No. of sprays \\
\hline & 2001 & UK & HT oilseed rape & 1.69 & 1.91 & 33 & No. of sprays \\
\hline \multirow[t]{4}{*}{ Zhao et al. (2011) } & 2005 & China & Bt cotton & 23 & 17 & 69 & No. of sprays \\
\hline & 2006 & China & Bt cotton & 22 & 13 & 63 & No. of sprays \\
\hline & 2007 & China & Bt cotton & 17 & 12 & 90 & No. of sprays \\
\hline & 2008 & China & Bt cotton & 16 & 11 & 97 & No. of sprays \\
\hline Bambawale et al. (2004) & 2003 & India & Bt cotton & 3 & 9 & 7 & No. of sprays \\
\hline Bennet et al. (2004b) & 2002 & South Africa & Bt cotton & 3.8 & 11.2 & 8 & No. of sprays \\
\hline \multirow[t]{2}{*}{ Pray et al. (2002) } & 2000 & China & Bt cotton & 20.5 & 48.5 & 122 & No. of sprays \\
\hline & 2001 & China & Bt cotton & 32.9 & 87.5 & 176 & No. of sprays \\
\hline
\end{tabular}




\begin{tabular}{|c|c|c|c|c|c|c|c|}
\hline Scientific Reference & Year & Country & Trait/ Crop & $\begin{array}{r}\text { Mean } \\
\text { GM }\end{array}$ & $\begin{array}{l}\text { Mean } \\
\text { Conv. }\end{array}$ & $\begin{array}{c}\text { No. } \\
\text { observations }\end{array}$ & Units \\
\hline \multirow[t]{2}{*}{ Traxler et al. (2003) } & 1997 & Mexico & Bt cotton & 2.98 & 5.24 & 59 & No. of sprays \\
\hline & 1998 & Mexico & Bt cotton & 1.55 & 4.6 & 87 & No. of sprays \\
\hline \multirow[t]{6}{*}{ Fitt (2003) } & 1997 & Australia & Bt cotton & 5 & 10.3 & 210 & No. of sprays \\
\hline & 1998 & Australia & Bt cotton & 6 & 10.2 & 179 & No. of sprays \\
\hline & 1999 & Australia & Bt cotton & 8.7 & 14 & 110 & No. of sprays \\
\hline & 2000 & Australia & Bt cotton & 6.2 & 10.3 & 149 & No. of sprays \\
\hline & 2001 & Australia & Bt cotton & 4.6 & 9.9 & 142 & No. of sprays \\
\hline & 2002 & Australia & Bt cotton & 3.1 & 8.6 & 229 & No. of sprays \\
\hline \multirow[t]{3}{*}{ Gomez-barbero et al. (2008) } & 2004 & Spain & Bt maize & 1.9 & 6.4 & 42 & No. of sprays \\
\hline & 2004 & Spain & Bt maize & 0.68 & 1.97 & 52 & No. of sprays \\
\hline & 2004 & Spain & Bt maize & 4.16 & 9.61 & 71 & No. of sprays \\
\hline \multirow[t]{2}{*}{ Pemsl et al. (2004) } & 2003 & India & Bt cotton & 2 & 3.7 & 11 & No. of sprays \\
\hline & 2004 & India & Bt cotton & 2.3 & 2.8 & 66 & No. of sprays \\
\hline \multirow[t]{2}{*}{ Krishna and Qaim (2012) } & 2002-2004 & India & Bt cotton & 4.41 & 7 & 298 & No. of sprays \\
\hline & 2006-2008 & India & Bt cotton & 3.47 & 3.47 & 62 & No. of sprays \\
\hline \multirow[t]{4}{*}{ Stone (2011) } & 2003-2007 & India & Bt cotton & 5.1 & 11.9 & 59 & No. of sprays \\
\hline & 2003-2007 & India & Bt cotton & 4 & 6.9 & 16 & No. of sprays \\
\hline & 2003-2007 & India & Bt cotton & 3.9 & 7.3 & 30 & No. of sprays \\
\hline & 2003-2007 & India & Bt cotton & 5.5 & 10.7 & 26 & No. of sprays \\
\hline Luttrell and Jackson (2012) & 2000-07 & USA & Bt cotton & 3.85 & 4.97 & 41 & No. of sprays \\
\hline Kouser and Qaim (2013) & 2005-2008 & Pakistan & Bt cotton & 1.52 & 2.22 & 385 & No. of sprays \\
\hline \multirow[t]{2}{*}{ Qaim and de Janvry (2005) } & 2000 & Argentina & Bt maize & 0.64 & 1.15 & 29 & $\mathrm{Kg}$ of active ingredient/ ha \\
\hline & 2001 & Argentina & Bt maize & 0.78 & 1.08 & 73 & $\mathrm{Kg}$ of active ingredient/ ha \\
\hline \multirow[t]{3}{*}{ Morse et al. (2006) } & 1999 & South Africa & Bt cotton & 0.49 & 1.05 & 87 & $\mathrm{Kg}$ of active ingredient/ ha \\
\hline & 2000 & South Africa & Bt cotton & 0.95 & 1.58 & 112 & $\mathrm{Kg}$ of active ingredient/ ha \\
\hline & 2001 & South Africa & Bt cotton & 0.75 & 1.99 & 245 & $\mathrm{Kg}$ of active ingredient/ ha \\
\hline Qaim and Zilberman (2003) & 2001 & India & Bt cotton & 0.48 & 1.55 & 157 & $\mathrm{Kg}$ of active ingredient/ ha \\
\hline \multirow[t]{2}{*}{ Krishna and Qaim (2012) } & 2002-2004 & India & Bt cotton & 1.55 & 2.46 & 298 & $\mathrm{Kg}$ of active ingredient/ ha \\
\hline & 2006-2008 & India & Bt cotton & 1.24 & 1.19 & 62 & $\mathrm{Kg}$ of active ingredient/ ha \\
\hline Huang et al. (2005) & 2003 & China & GM rice & 2 & 21.2 & 123 & $\mathrm{Kg}$ of pesticide/ ha \\
\hline
\end{tabular}




\begin{tabular}{|c|c|c|c|c|c|c|c|}
\hline Scientific Reference & Year & Country & Trait/ Crop & $\begin{array}{c}\text { Mean } \\
\text { GM }\end{array}$ & $\begin{array}{l}\text { Mean } \\
\text { Conv. }\end{array}$ & $\begin{array}{c}\text { No. } \\
\text { observations }\end{array}$ & Units \\
\hline \multirow[t]{2}{*}{ Wossink and Denaux (2006) } & 2000 & USA & HT cotton & 12.35 & 15.69 & 44 & $\mathrm{Kg}$ of pesticide/ ha \\
\hline & 2001 & USA & Stacked cotton & 9.79 & 15.69 & 44 & $\mathrm{Kg}$ of pesticide/ ha \\
\hline Nelson and Bullock (2003) & 1997 & USA & HT soybean & 3.91 & 17.49 & 500 & $\mathrm{Kg}$ of pesticide/ ha \\
\hline Qaim and Zilberman (2003) & 2001 & India & Bt cotton & 1.74 & 5.56 & 157 & $\mathrm{Kg}$ of pesticide/ ha \\
\hline Huang et al. (2005) & 1999 & China & Bt cotton & 11.8 & 60.7 & 45 & $\mathrm{Kg}$ of pesticide/ ha \\
\hline Qaim et al. (2006) & 2003 & India & Bt cotton & 5.12 & 10.30 & 133 & $\mathrm{Kg}$ of pesticide/ ha \\
\hline Kouser and Qaim (2013) & $2005-2008$ & Pakistan & Bt cotton & 3.16 & 8.74 & 385 & $\mathrm{Kg}$ of pesticide/ ha \\
\hline \multirow[t]{2}{*}{ Hofs et al. (2006) } & 2003 & South Africa & Bt cotton & 2.14 & 1.41 & 10 & Litre/ ha \\
\hline & 2004 & South Africa & Bt cotton & 2.99 & 3.47 & 10 & Litre/ ha \\
\hline Shankar et al. (2008) & 2000 & South Africa & Bt cotton & 1.6 & 2.4 & 33 & Litre/ ha \\
\hline \multirow[t]{3}{*}{ Qaim and Traxler (2005) } & 2001 & Argentina & HT soybean & 0.07 & 0.42 & 59 & Litre/ ha \\
\hline & 2002 & Argentina & HT soybean & 0 & 0.68 & 59 & Litre/ ha \\
\hline & 2003 & Argentina & HT soybean & 5.5 & 1.58 & 59 & Litre/ ha \\
\hline
\end{tabular}

760 
Figure A-1a. Density plots for individual environmental impact indicators using min-max normalising method for GM and conventional crops

I1: Number of individuals (arthropods)

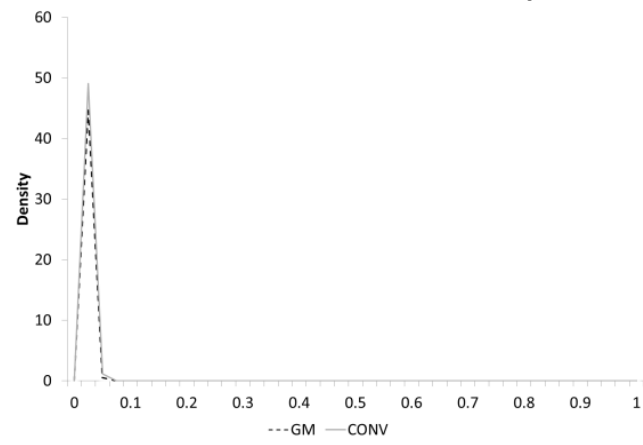

13: Number of individuals(arthropods) per 100 plants

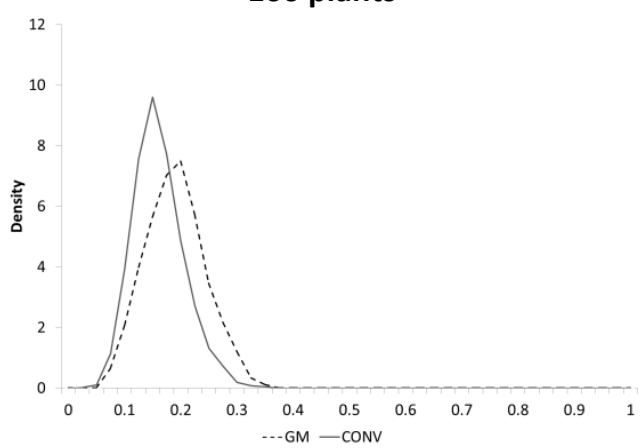

15: Number of sprays

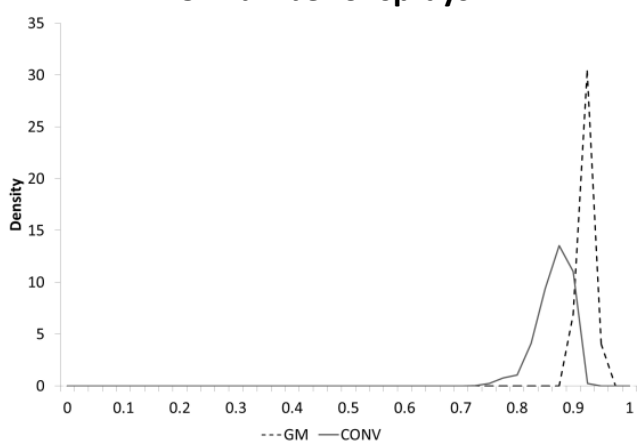

17: Kg insecticide/ha

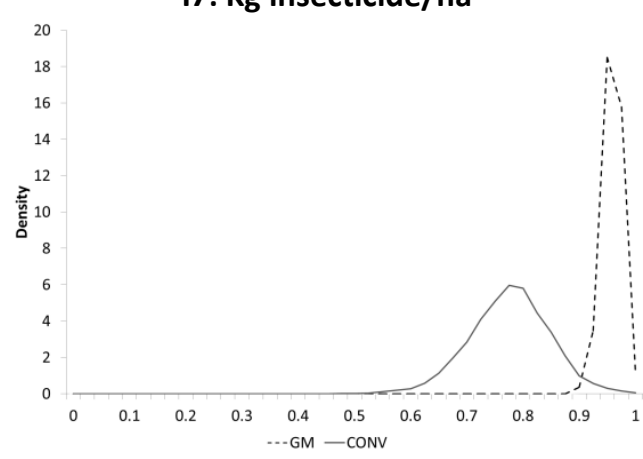

12: Number of individuals (birds)

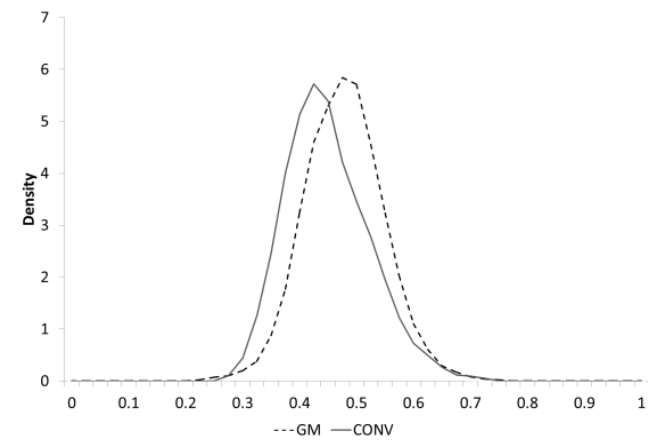

14: Weight $\left(\mathrm{mg} / \mathrm{m}^{2}\right)$

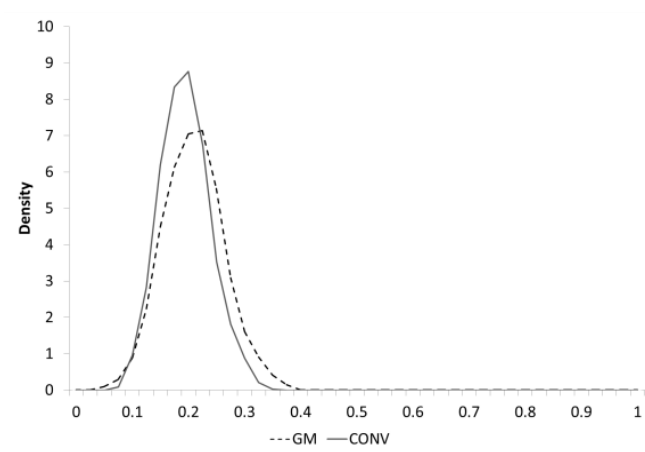

16: Kg active ingredient/ha

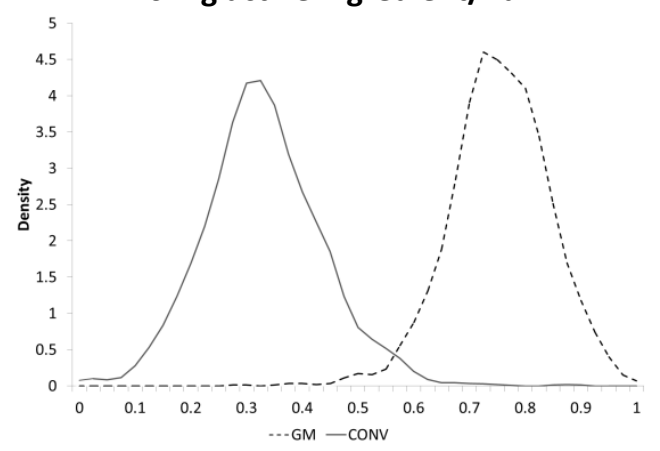

18: Litre/ha

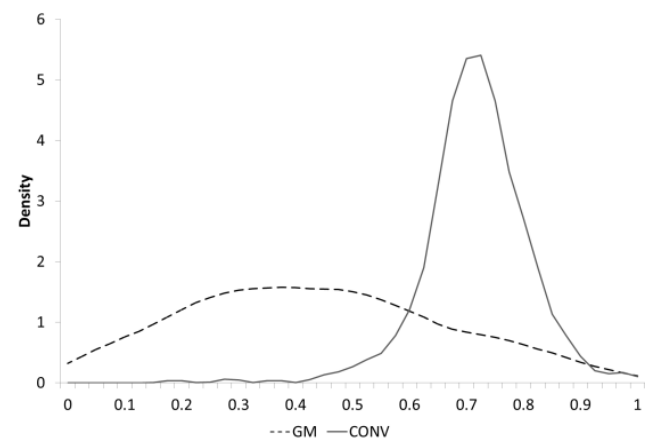




\section{method for GM and conventional crops}

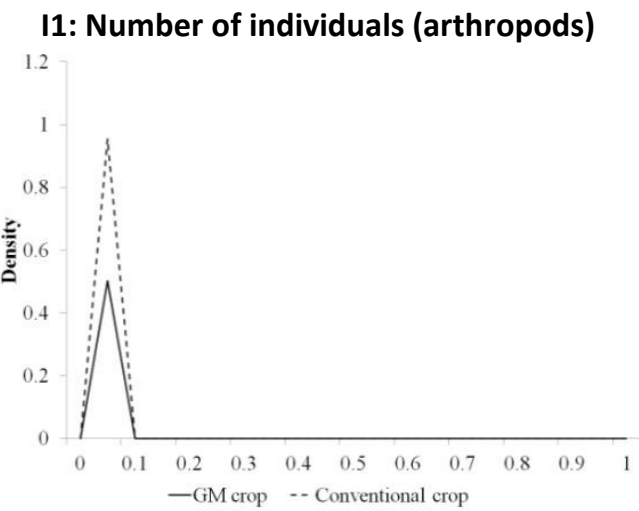

13: Number of individuals(arthropods) per 100 plants

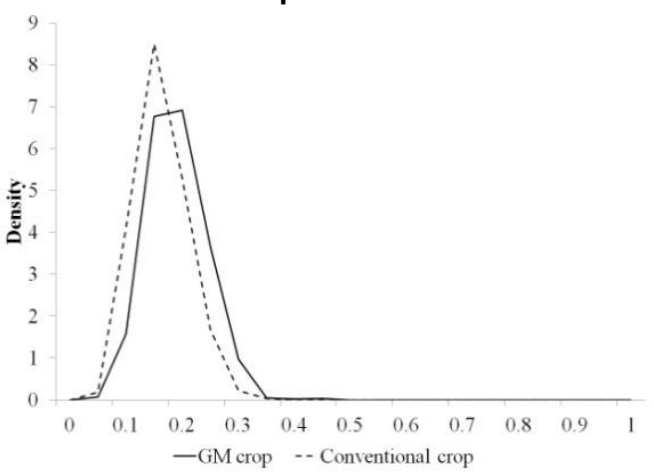

12: Number of individuals (birds)

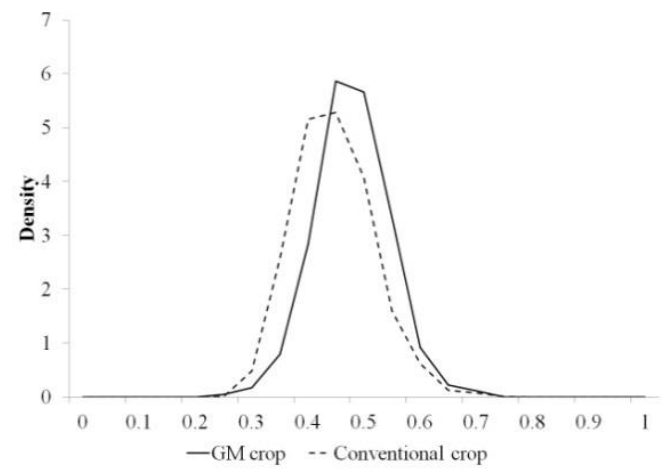

14: Weight (mg/m2)

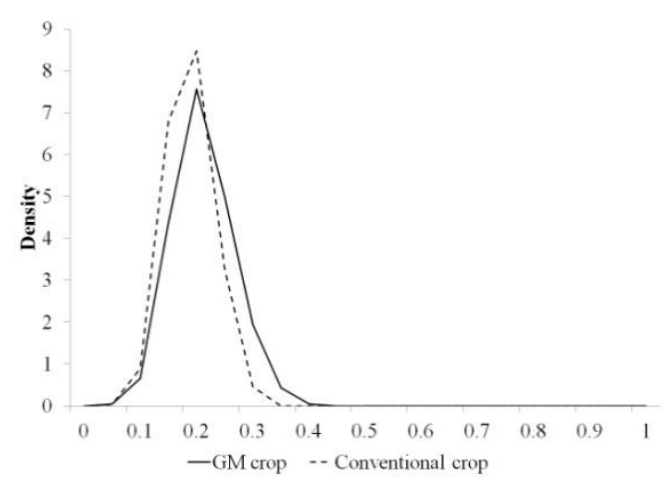

15: Number of sprays

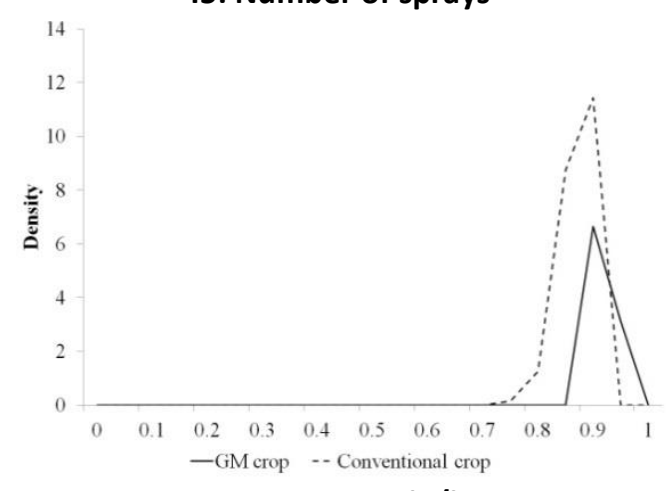

16: Kg active ingredient/ha

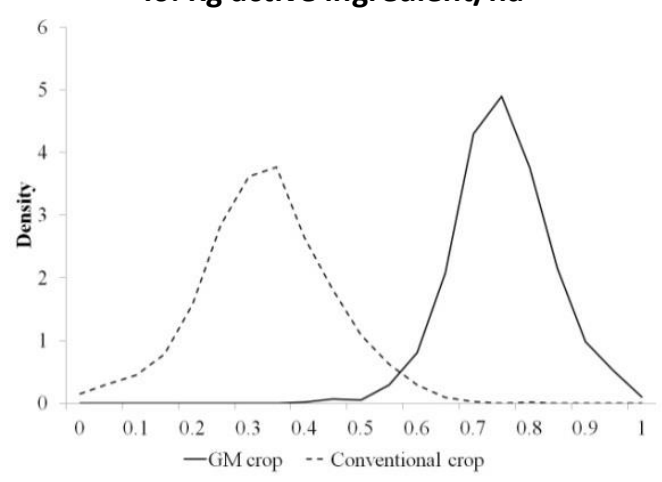

18: Litre/ha
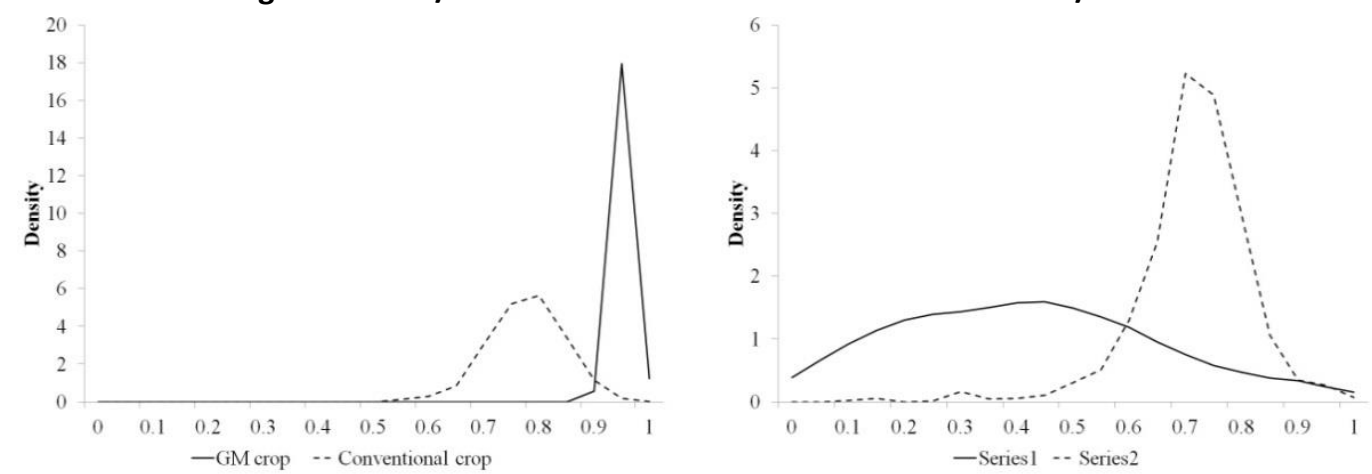


\begin{tabular}{lccccc}
\hline & \multicolumn{2}{c}{ GM } & \multicolumn{2}{c}{ Conventional } & \multirow{2}{*}{ Pr (GM>Conv) } \\
& Mean & Std. Dev & Mean & Std. Dev & \multirow{2}{*}{0.504} \\
\hline $\begin{array}{l}\text { I1. Number of individuals } \\
\text { (arthropods) }\end{array}$ & 0.024 & 0.008 & 0.024 & 0.008 & 0.622 \\
I2. Number of individuals (birds) & 0.495 & 0.062 & 0.466 & 0.067 & 0.663 \\
I3. Number of individuals & 0.191 & 0.051 & 0.162 & 0.045 & 0.589 \\
(arthropods) per 100 plants & & & & & 0.986 \\
I4. Earthworm weight (mg/m ${ }^{2}$ ) & 0.209 & 0.053 & 0.193 & 0.045 & 0.996 \\
I5. Number of sprays & 0.922 & 0.014 & 0.863 & 0.031 & 0.991 \\
I6. Kg active ingredient per ha & 0.609 & 0.075 & 0.266 & 0.089 & 0.148 \\
I7. Kg insecticide per ha & 0.933 & 0.017 & 0.757 & 0.069 & 0.072 \\
I8. Litre per ha & 0.337 & 0.190 & 0.541 & &
\end{tabular}

772

773

774 
Figure A-2. Density plots for the average composite indicators using the min-max normalising method and additive and multiplicative aggregation methods for GM and conventional crops
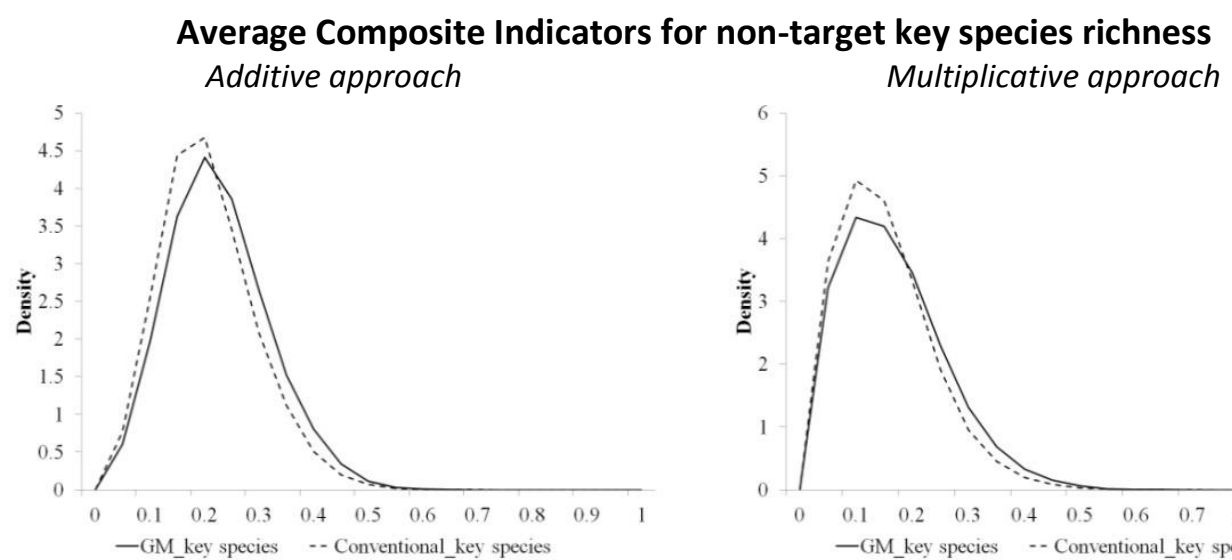

Average Composite Indicators for pesticide use

Additive approach

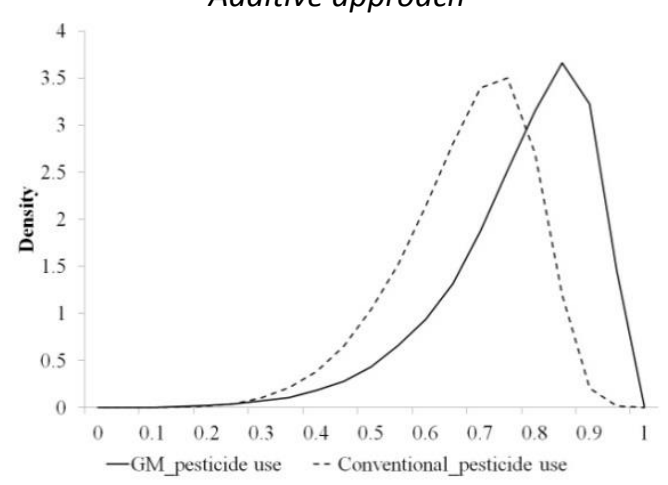

Multiplicative approach

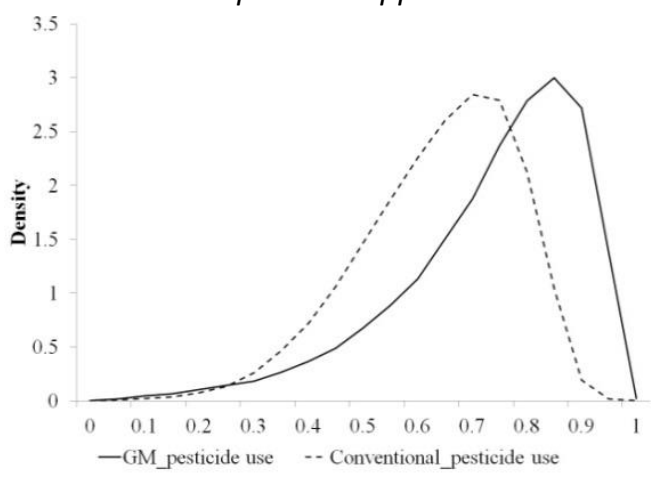

Table A-4. Non-target key species richness and pesticides composite indicators results for GM and conventional crops (using distance and the additive/multiplicative methods)

\begin{tabular}{lccccc}
\hline & \multicolumn{2}{c}{ GM } & \multicolumn{2}{c}{ Conventional } & \multirow{2}{*}{ Pr (GM>Conv) } \\
& Mean & Std. Dev & Mean & Std. Dev & \multirow{2}{*}{0.66} \\
\hline Addition & & & & & \\
Non-target key species richness CI & 0.23 & 0.10 & 0.21 & 0.09 & 0.80 \\
$\begin{array}{l}\text { Pesticide use CI } \\
\text { Multiplicative }\end{array}$ & 0.70 & 0.15 & 0.61 & 0.13 & 0.63 \\
Non-target key species richness CI & 0.17 & 0.09 & 0.16 & 0.09 & 0.72 \\
Pesticide use CI & 0.65 & 0.18 & 0.57 & 0.14 & \\
\hline
\end{tabular}


Figure A-3. Density plots for the overall environmental composite indicator using the min-max normalising method and the additive aggregation methods (I)

Cl 1

Weight to non-target species $=0$ Weight to pesticide use $=1$

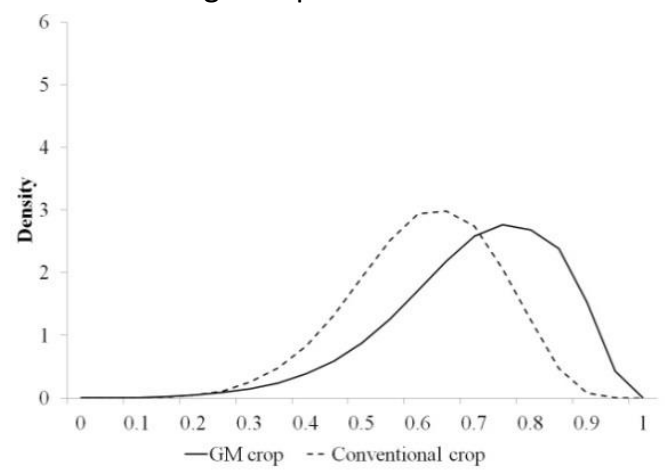

$\mathrm{Cl} 3$

Weight to non-target species $=0.2$ Weight to pesticide use $=0.8$

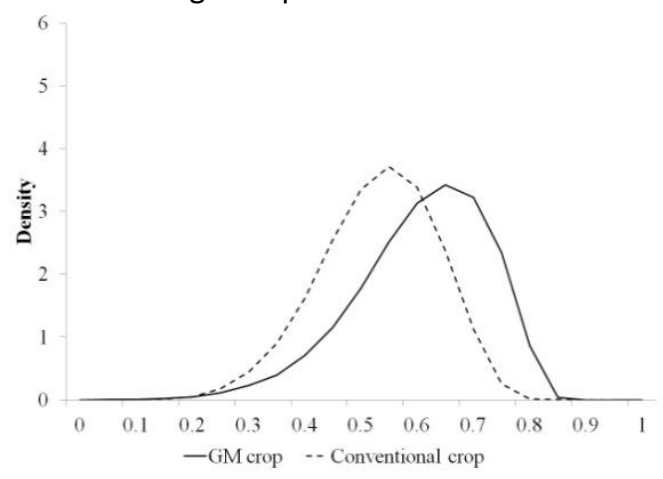

Cl 5

Weight to non-target species $=0.4$ Weight to pesticide use $=0.6$

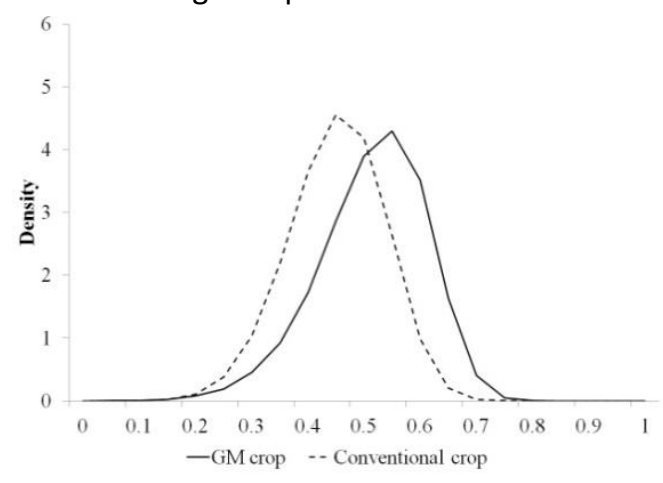

CI7

Weight to non-target species $=0.6$ Weight to pesticide use $=0.4$
$\mathrm{Cl} 2$

Weight to non-target species $=0.1$ Weight to pesticide use $=0.9$

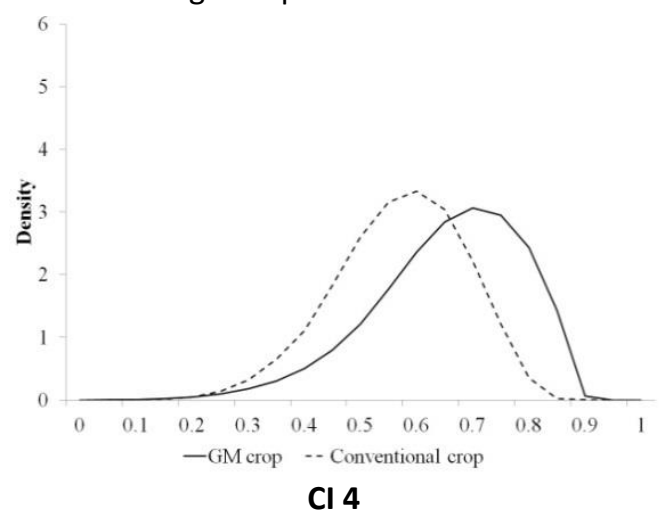

Weight to non-target species $=0.3$ Weight to pesticide use $=0.7$

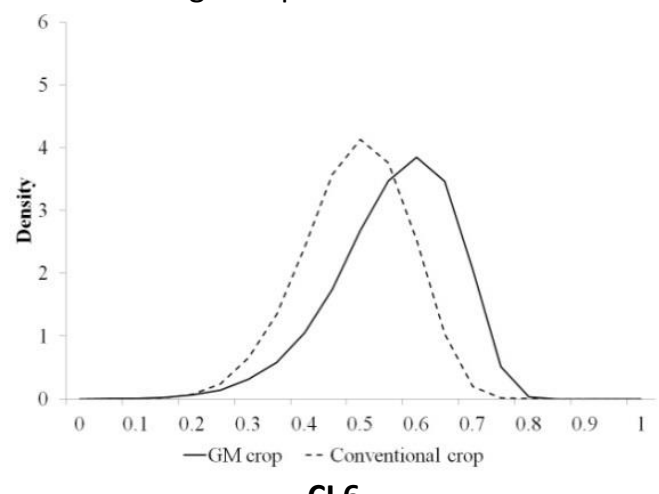

$$
\text { CI } 6
$$

Weight to non-target species $=0.5$ Weight to pesticide use $=0.5$

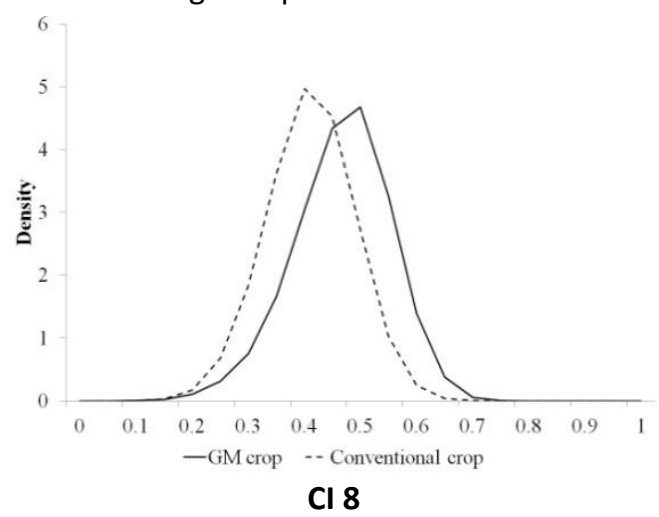

Weight to non-target species $=0.7$ Weight to pesticide use $=0.3$ 
Figure A-3. Density plots for the overall environmental composite indicator using the min-max normalising method and the additive aggregation methods (II)

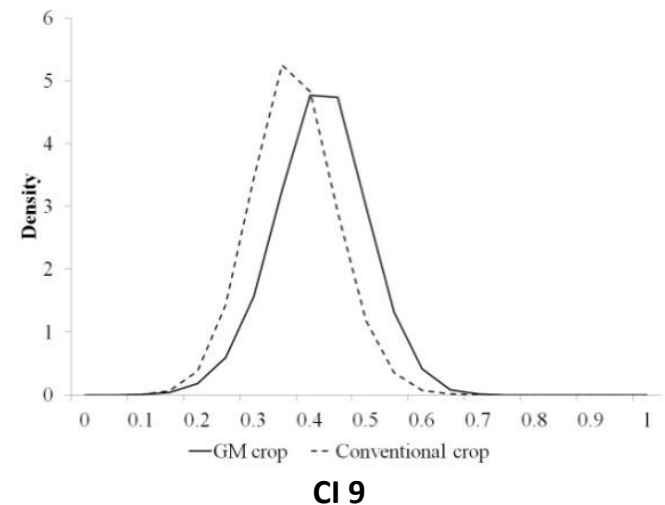

Weight to non-target species $=0.8$

Weight to pesticide use $=0.2$

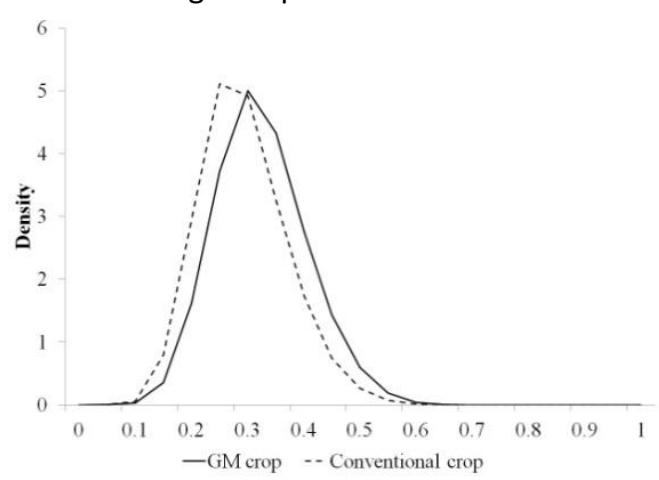

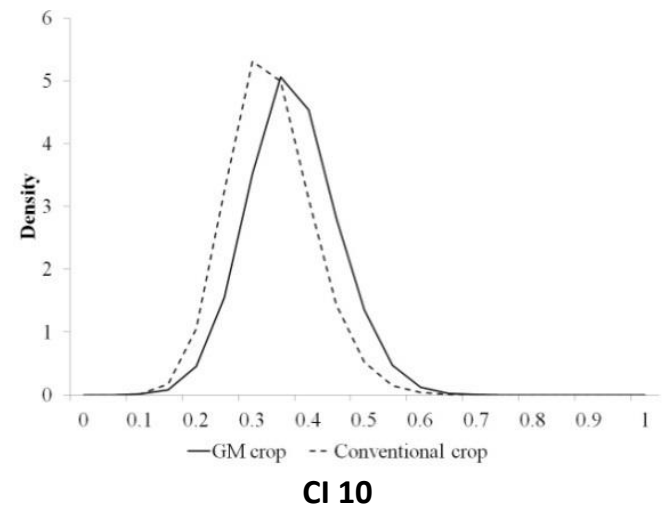

Weight to non-target species $=0.9$ Weight to pesticide use $=0.1$

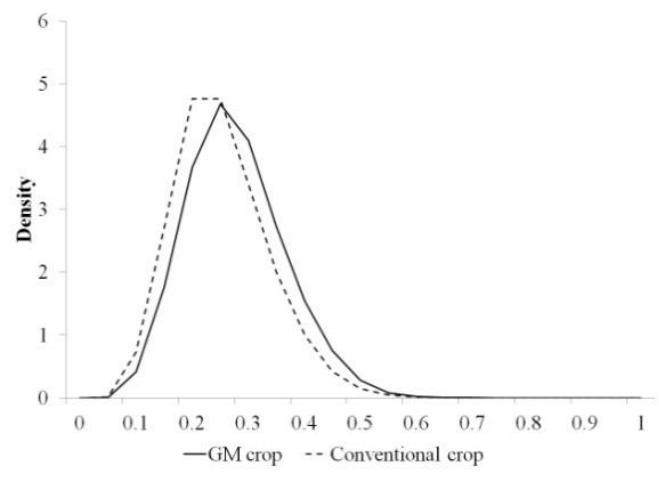

Cl11

Weight to non-target species $=1$

Weight to pesticide use $=0$

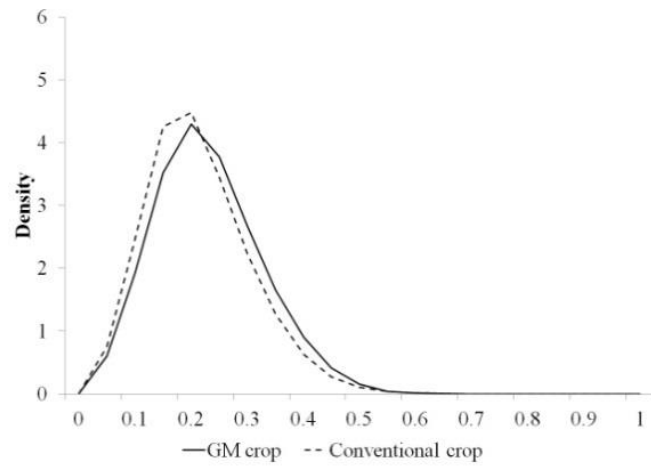

